\title{
A new and very spiny lizard (Gymnophthalmidae: Echinosaura) from the Andes in northwestern Ecuador
}

\author{
Mario H. Yánez-Muñoz ${ }^{1,2}$, Omar Torres-Carvajal ${ }^{3}$, Juan P. Reyes-Puig ${ }^{1,2}{ }^{2}$, Miguel A. Urgiles-Merchán ${ }^{1}$, Claudia \\ Koch ${ }^{\text {Corresp. } 4}$ \\ 1 Unidad de Investigación, Instituto Nacional de Biodiversidad (INABIO), Quito, Ecuador \\ 2 Fundación Red de Protección de Bosques ECOMINGA, Fundación Oscar Efrén Reyes, Departamento de Ambiente, Baños, Ecuador \\ 3 Museo de Zoología, Escuela de Ciencias Biológicas, Pontificia Universidad Católica del Ecuador, Quito, Ecuador \\ 4 Herpetology, Zoologisches Forschungsmuseum Alexander Koenig (ZFMK), Bonn, Germany \\ Corresponding Author: Claudia Koch \\ Email address: c.koch@zfmk.de
}

We describe a new species of Neotropical spiny-lizard of the genus Echinosaura from the Imbabura and Carchi Provinces on the western slopes of the Andes in northwestern Ecuador. The new species mostly resembles E. horrida. However, it can be distinguished from all congeners by having keeled enlarged dorsal scales forming a paired vertebral row, two paravertebral series of short oblique rows of projecting scales, and a pair of spine-like scales on temporal and nuchal regions. We also provide a detailed description of the osteology of the skull and pectoral girdle of the new species and present a phylogenetic hypothesis for Echinosaura based on three mitochondrial genes (12S, 16S, ND4) and one nuclear gene (c-mos). 


\section{A new and very spiny lizard (Gymnophthalmidae:}

2 Echinosaura) from the Andes in northwestern

3 Ecuador

Mario H. Yánez-Muñoz ${ }^{1,2}$, Omar Torres-Carvajal ${ }^{3}$, Juan P. Reyes-Puig ${ }^{1,2}$, Miguel A. Urgiles-

Merchán ${ }^{1}$, and Claudia Koch ${ }^{4 *}$

${ }^{1}$ Unidad de Investigación, Instituto Nacional de Biodiversidad (INABIO), Quito, Ecuador.

${ }^{2}$ Fundación Red de Protección de Bosques ECOMINGA, Fundación Oscar Efrén Reyes, Departamento de Ambiente, Baños, Ecuador.

${ }^{3}$ Museo de Zoología, Escuela de Ciencias Biológicas, Pontificia Universidad Católica del Ecuador, Quito, Ecuador.

${ }^{4}$ Herpetology, Zoologisches Forschungsmuseum Alexander Koenig (ZFMK), Bonn, Germany.

*Corresponding Author:

Claudia $\mathrm{Koch}^{4}$

Email address: c.koch@leibniz-zfmk.de

\section{Abstract}

We describe a new species of Neotropical spiny-lizard of the genus Echinosaura from the Imbabura and Carchi Provinces on the western slopes of the Andes in northwestern Ecuador. The new species mostly resembles E. horrida. However, it can be distinguished from all congeners by having keeled enlarged dorsal scales forming a paired vertebral row, two paravertebral series of short oblique rows of projecting scales, and a pair of spine-like scales on temporal and nuchal regions.

We also provide a detailed description of the osteology of the skull and pectoral girdle of the new species and present a phylogenetic hypothesis for Echinosaura based on three mitochondrial genes (12S, 16S, ND4) and one nuclear gene (c-mos).

\section{Introduction}

Neotropical spiny-lizards traditionally ranked as the genus Echinosaura Boulenger 1890 are small riparian lizards occuring west of the Andes from Panama to Ecuador (Vásquez-Restrepo et al., 2020). Most species of Echinosaura have partially compressed tails and bear enlarged tubercles and strongly keeled scales on body and tail, often forming crests, which represent adaptations for aquatic locomotion (Marques-Souza et al., 2018). 
60

Recent molecular phylogenetic studies have resulted in major taxonomic changes within Echinosaura, such as synonymy of Teuchocercus Fritts \& Smith 1969 with Echinosaura and description of Centrosaura Uzzell 1966 and Rheosaurus Vásquez-Restrepo, Ibáñez, SánchezPacheco \& Daza 2020, to accommodate "E. apodema” Uzzell 1966 and "E. sulcarostrum" Donnelly, Macculloch, Ugarte \& Kizirian 2006, respectively (Torres-Carvajal et al., 2016; Vásquez-Restrepo et al., 2020).

Of the seven currently recognized species of Echinosaura, four are known from Ecuador: $E$. brachycephala, E. horrida, E. keyi and E. orcesi, all from western humid tropical and subtropical areas (Torres-Carvajal et al., 2021).

In extreme northwestern Ecuador, specifically in Carchi province near the national border with Colombia, important remnants of native vegetation are still preserved due to inaccessibility and local conservation initiatives. During the last six years, we have focused on the study and conservation of this important biodiversity area, discovering several new species and many candidate species of small vertebrates that are still awaiting formal description (Yánez-Muñoz et al., 2018; Reyes-Puig et al., 2020; Brito et al., 2020). Here, we describe a new species of Echinosaura recognized and delimited by a molecular phylogenetic analysis along with several types of morphological evidence, including cranial osteology. Accordingly, the first detailed description of the cranial morphology of Echinosaura based on CT scan data of the new species is presented.

\section{Materials and Methods}

Ethics statement. We conducted this study under research permits MAE-DNB-CM-2016-0045 and MAE-DNB-CM-2019-0120, issued by the Ministerio del Ambiente del Ecuador. We followed the guidelines for use of live amphibians and reptiles in field research (Beaupre et al., 2004), compiled by the American Society of Ichthyologists and Herpetologists, the Herpetologists' League and the Society for the Study of Amphibians and Reptiles.

Taxon sampling. We examined 36 specimens of Echinosaura (Appendix) housed in the following collections: División de Herpetología del Instituto Nacional de Biodiversidad (DHMECN), Quito, Ecuador; Museo de Zoología de la Pontificia Universidad Católica del Ecuador (QCAZ), Quito, Ecuador; Natural History Museum (BMNH), London, UK; University of Illinois Museum of Natural History (UIMNH), Illinois, USA; Muséum d'Histoire Naturelle de la Ville de Genève (MHNG), Geneva, Switzerland; Natural History Museum Vienna (NMW), Vienna, Austria; Zoological Research Museum Alexander Koenig (ZFMK), Bonn, Germany. We mapped locality records using ArcMap 10.5.1 (ESRI, Inc.) with a WGS84 datum and Universal Transverse Mercator conformal projection.

We adopted the unified species concept (de Queiroz, 2007) by considering different lines of evidence (e.g., external morphology, osteology, hemipenial morphology, molecular phylogeny) 
as species delimitation criteria. We considered monophyly as additional evidence for recognizing populations as new species. The electronic version of this article in Portable Document Format (PDF) will represent a published work according to the International Commission on Zoological Nomenclature (ICZN), and hence the new names contained in the electronic version are effectively published under that Code from the electronic edition alone. This published work and the nomenclatural acts it contains have been registered in ZooBank, the online registration system for the ICZN. The ZooBank LSIDs (Life Science Identifiers) can be resolved, and the associated information viewed through any standard web browser by appending the LSID to the prefix http://zoobank.org/. The LSID for this publication is:

urn:lsid:zoobank.org:pub:9D513A0D-D676-4290-AE5D-A128B7DBE3F3.

Field work. We conducted field work in the foothill forests of Carchi province associated with several small river basins during a joint expedition of Instituto Nacional de Biodiversidad (INABIO) and Ecominga Foundation in three sectors of the Dracula Reserve: (1) Río Pailón Chico (0.982, -78.233; 1,224 m), 6-11 November 2017 and 19-25 August 2018; (2) Guapilal (0.891, -78.203; 1,640-1,750 m), 22-26 April 2019; (3) Cerro Oscuro (0.886, -78.190; 1,600 m), 4-6 July 2020; and (4) Bosque Comunal La Esperanza (0.954, -78.237; 1,439-1,623 m), 22-31 March 2021. We collected the specimens using visual encounter surveys and pitfall traps (Fitzgerald, 2012) and after photographing them alive, we euthanized the animals with benzocaine, extracted a sample of muscle tissue from each individual and preserved the samples in $95 \%$ ethanol. Subsequently, we fixed the specimens in $10 \%$ formalin, and preserved in $75 \%$ ethanol.

Morphological data and analysis. Following Vásquez-Restrepo et al. (2020), we recorded the following 12 morphometric characters with a digital caliper (Trupper, precision $\pm 0.01 \mathrm{~mm}$, rounded to $0.1 \mathrm{~mm}$ ) using a 10x Boeco BS-80 stereo microscope: snout-vent length (SVL), measured from tip of snout to cloacal opening; trunk length (TRL), measured longitudinally from axilla to groin; tail length (TAL), measured from cloacal opening to tip of tail; snout length (SL), measured from tip of snout to anterior edge of eye; head length (HL), measured from tip of snout to anterior edge of tympanum; head width (HW), measured at level of greatest width; humerus length (HUM), measured from edge of joint to edge of shoulder; forearm length (FAL), measured from edge of joint to base of hand; hand length (HND), measured from base of hand to tip of fourth finger; femur length (FEM), measured from groin to outer edge of knee; tibia length (TIB), measured from outer edge of knee to base of foot; foot length (FTL), measured from base of foot to tip of fourth toe. Except for males with everted hemipenes, we determined the sex by subcaudal incision, or by secondary sexual characteristics like the number of femoral pores. We used the terminology proposed by Fritts, Almendáriz \& Samec (2002), Köhler, Böhme \& Schmitz (2004), and Vásquez-Restrepo et al. (2020) for scale characters and measurements. We obtained data of color in life from field notes and photographs.

We extracted the right hemipenis of the male holotype (DHMECN 15208) from the recently collected specimenand then filled the extracted organ with blue-stained petroleum jelly and immersed it in a solution of alizarin red for two hours. Thereafter we washed the hemipenis to 
120

121

122

123

124

125

126

127

128

129

130

131

132

133

134

135

136

137

138

139

140

141

142

143

144

145

146

147

148

149

150

151

152

153

154

155

156

157

158

159

160

remove excess alizarin red and finally transferred to $70 \%$ ethanol. Terminology for hemipenial structures follows Uzzell (1973), Savage (1997) and Nunes et al. (2012).

We obtained information on skeletal morphology and stomach contents from two specimens of the new species (DHMECN 15210, DHMECN 15208) by use of an X-ray in 2D (Faxitron X-ray LX60) and a micro-CT scanner (Bruker SkyScan 1173) in 3D, both devices available at ZFMK. We placed the specimens in a plastic container and mounted it on styrofoam to avoid movements during scanning. We CT-scanned the specimens in $180^{\circ}$ degrees using rotation steps of $0.3^{\circ}$ degrees with a tube voltage of $35 \mathrm{kV}$ and a tube current of $150 \mathrm{uA}$, without the use of a filter, at an image resolution of $39.3 \mu \mathrm{m}$. Scan duration was $30 \mathrm{~min}$ with an exposure time of $280 \mathrm{~ms}$. We reconstructed the CT-datasets using N-Recon software (Bruker MicroCT) and rendered both scans in three dimensions with the program CTVox version 2.6 (Bruker MicroCT). Additionally, we rendered and segmented the skull of a female paratype (DHMECN 15210) in three dimensions to separate and color individual bones through the aid of Amira visualization software (FEI, Thermo Fisher Scientific). We provide a detailed description of the skull, vertebrae and pectoral girdle based on data of the female paratype (DHMECN 15210). We omitted cartilage structures because micro-CT does not render cartilage. Osteological terminology follows Evans (2008), Jerez \& Tarazona (2009), Roscito \& Rodrigues (2010), Rodrigues et al. (2013), and Hernández Morales et al. (2019).

DNA sequence data and phylogenetic analyses. We digested and extracted total genomic DNA from liver or muscle tissue using a guanidinium isothiocyanate extraction protocol. Using primers and amplification protocols from the literature (Torres-Carvajal et al., 2016), we generated DNA sequences of mitochondrial genes 12S, 16S, and ND4, as well as nuclear gene cmos from two individuals of the new species described herein (GenBank accession numbers [DHMECN 14058 and 15208, respectively] MW525208-09 [12S], MW525211-12 [16S], MW512698-699 [ND4], and MW512700-701 [c-mos]). We retrieved all available GenBank sequences of these genes for other Echinosaura species, as well one sample per species of all clades ranked as genera within Cercosaurinae including "unnamed" clades (Torres-Carvajal et al., 2016).

We aligned DNA sequences using MAFFT (Katoh \& Standley, 2013) under default settings in Geneious Prime 2020.2.2 (https://www.geneious.com), and translated ND4 and c-mos sequences into amino acids for confirmation of alignment. Our final concatenated data matrix contained 148 taxa and 1,935 characters and was partitioned by gene and codon position (i.e., eight partitions total). We chose the best partitioning scheme using PartitionFinder v2.1.1 under the Bayesian Information Criterion (BIC), and the "greedy" algorithm with branch lengths of alternative partitions "linked" to search for the best-fit scheme (Guindon et al., 2010; Lanfear et al., 2012; Lanfear et al., 2017). We combined the genes into a single dataset with six partitions: (i) $12 \mathrm{~S}, 16 \mathrm{~S}$ [GTR + I + G]; (ii) 1st codon position of ND4 [GTR + I + G]; (iii) 2nd codon position of ND4 [GTR + I + G]; (iv) 3rd codon position of ND4 [GTR + G]; (v) 3rd codon position of c-mos $[\mathrm{K} 80+\mathrm{G}]$; and (vi) 1st and 2nd codon positions of c-mos $[\mathrm{HKY}+\mathrm{G}]$. We run 
161 a maximum likelihood analysis in RAxML v8.2.10 (Stamatakis, 2014) under the GTRGAMMA

162 model, while we assessed nodal support with the rapid bootstrapping (BS) algorithm

163 (Stamatakis, Hoover \& Rougemont, 2008) on 1,000 replicates. We run a Bayesian analysis in

164 MrBayes v3.2.7 (Ronquist et al., 2012), with all parameters unlinked between partitions (except

165 topology and branch lengths) and rate variation (prset ratepr = variable) invoked. We set four

166 independent runs, each with four MCMC chains, for 107 generations, sampling every 10,000

167 generations. We calculated posterior probabilities (PP) on a Maximum Clade Credibility Tree in

168 TreeAnnotator (Rambaut \& Drummond, 2016) and rooted the trees with Alopoglossus (Castoe,

169 Doan \& Parkinson, 2004; Goicoechea et al., 2016; Pellegrino et al., 2001). We executed

170 phylogenetic analyses in the CIPRES Science Gateway (Miller, Pfeiffer \& Schwartz, 2010). In

171 addition, we calculated pairwise genetic distances for ND4 and 16S genes among species of

172 Echinosaura using DIVEIN (Deng et al., 2010).

173

174

\section{Results}

175

176

177

Phylogenetic relationships. Maximum likelihood and Bayesian analyses resulted in nearly

178 identical topologies (Fig. 1). Both analyses support monophyly of the new species of

Echinosaura described in this paper. The monophyly of Echinosaura is maximally supported $(\mathrm{BS}=100, \mathrm{PP}=1)$. There is a basal split into two clades, one of which $(\mathrm{BS}=96, \mathrm{PP}=1)$ contains E. orcesi as sister to (E. panamensis, (E. centralis, E. palmeri)). The second clade $(\mathrm{BS}=$ $53, \mathrm{PP}=1$ ) includes, following branching order, E. keyi, E. brachycephala (sister to E. keyi in the ML tree), and the new species described below as sister to E. horrida with strong support $(\mathrm{BS}=98, \mathrm{PP}=1)$. Uncorrected pairwise genetic distances for ND4 between Echinosaura sp. nov. and other congenerics range between 0.20 , with both $E$. horrida and E. keyi, and 0.35 with E. centralis. Distances for $16 \mathrm{~S}$ range from 0.06 with $E$. brachycephala to 0.14 with $E$. panamensis.

187

Systematic accounts

Squamata Oppel, 1811

190

Gymnophthalmidae Merrem, 1820

192

Echinosaura Boulenger, 1890

194

Echinosaura fischerorum sp. nov.

LSID: urn:Isid:zoobank.org:act:F8DCFE99-4862-4476-9A5C-EB684D0CD73A 
200

201

202

203

204

205

206

207

208

209

210

211

212

213

214

215

216

217

218

219

220

221

222

223

224

225

226

227

228

229

230

231

232

233

234

235

236

237

238

239

Holotype (Figs. 2, 3, 4, 5, 6, 7). DHMECN 15208, adult male, from Reserva Dracula, Sector El Guapilal (0.891, -78.203; 1,689 m), Carchi Province, Ecuador, collected on 22 April 2019 by Juan P. Reyes-Puig, Daniela Franco and Héctor Yela.

Paratypes (Figs. 4, 5, 6, 8, 9, 10). DHMECN 15209 and DHMECN 15211, adult males, DHMECN 15210, adult female, all with same data as holotype; DHMECN 14058 and DHMECN 14060, adult females, DHMECN 14059 and DHMECN 14061, juvenile females, all from Reserva Dracula, Sector El Pailón Chico (0.983, -78.296; 1,495 m), collected on 8 November 2017 by Mario H. Yanez-Muñoz, Juan P. Reyes-Puig and Fausto Recalde; DHMECN 12767, juvenile female from Cerro Oscuro, Reserva Dracula $(0.886,-78.190 ; 1,600 \mathrm{~m})$ collected on June 2015 by Héctor Yela; DHMECN 16109, adult female and DHMECN 16110, adult male, from Comunidad La Esperanza (0.954, -78.237; 1,623 m), collected on 28 March 2021 by Mario H. Yánez-Muñoz, Juan P. Reyes-Puig and Miguel A. Urgiles-Merchán.

Diagnosis. The new species can be distinguished from all congeners by the combination of the following characteristics: 1) snout pointed; 2) internasal single; 3 ) frontonasals paired; 4) frontal single; 5) frontoparietal paired; 6) supraoculars three, large; 7) supralabials five; 8) infralabials four; 9) postmental single; 10) chin shields enlarged, in one pair; 11) dorsum with a vertebral row of paired, enlarged, keeled scales; 12) two paravertebral series of short oblique rows of projecting scales, with scales increasing in size posteriorly on each row so that the most posterior scale of each row is a greatly enlarged, projecting spine; 13) spiny scales forming oblique lines on body flanks; 14) ventral scales squared, keeled; 15) subdigital lamellae on fourth finger 1418 ; 16) subdigital lamellae on fourth toe $24-27$; 17) femoral pores per hind limb in males 7-9; 18) dorsal surface of tail with two longitudinal rows of enlarged keeled scales that are more conspicuous on the anterior half of tail; 19) subcaudals per caudal segment three (anterior third of tail excluded); 20) tip of snout with creamy orange marks; 21) dorsal background dark brown with creamy orange paravertebral blotches extending onto anterior end of tail; 22) intense orange nuchal spines; 23) base of tail dorsally with a pair of pale orange blotches; 24) venter gray, marmorated with black and dark brown; 25) femoral pores yellowish cream; 26) premaxillary tooth loci $11-12$; 27) maxillary tooth loci 17-18; 28) dentary tooth loci 22-23; 29) nasal bones in medial contact along most of their length; 30) postfrontal expands posteriorly to form part of the anterior border of the supratemporal fenestra.

Comparison with similar species (Figs. 11, 12, 13, 14). Echinosaura fischerorum sp. nov. differs from all Echinosaura species in having keeled enlarged dorsal scales forming a paired vertebral row, two paravertebral series of short oblique rows of projecting scales, and a pair of spine-like scales on each side in temporal and nuchal region (see Table 1).

Echinosaura fischerorum sp. nov. most closely resembles E. horrida (character states in parentheses), but can be distinguished from this species in having a wide postmental in contact

PeerJ reviewing PDF | (2021:08:65159:1:1:NEW 18 Oct 2021) 
240

241

242

243

244

245

246

247

248

249

250

251

252

253

254

255

256

257

258

259

260

261

262

263

264

265

266

267

268

269

270

271

272

273

274

275

276

277

278

279

280

with anterior 3/4 of first infralabial (Fig. 3C; postmental longer than wide, in contact with first and second infralabials); keeled (smooth) enlarged dorsal scales forming a paired vertebral row; scales on each side of vertebral row heterogeneous in size (granular, homogeneous in size), with enlarged scales forming chevrons (Fig. 12A, B); sharp (blunt) spiny scales throughout body, forearms and legs; striated (smooth) dorsal and lateral head scales; keeled (smooth) parietals; nasal bones in medial contact along most of their length (distinctly separated, resulting in contact between premaxilla and frontal bone); postfrontal bone expands posteriorly to form part of the anterior border of the supratemporal fenestra (postfrontal excluded from the supratemporal fenestra by contact of postorbital with parietal). Although our sampling size is small, $E$. fischerorum sp. nov. seems to be smaller (maximum $\mathrm{SVL}=68 \mathrm{~mm}$ ) than E. horrida (maximum $\mathrm{SVL}=86 \mathrm{~mm})$.

Description of adult male holotype (Figs. 2, 3). Rostral single, in contact with internasal posteriorly, nasals and first supralabials posterolaterally; internasal single, wider than long, rugose, in contact with rostral anteriorly, nasals laterally, and frontonasals posteriorly; nasals pentagonal, in contact with rostral anteriorly, internasal and frontonasal dorsally, frenocular and lorilabial posteriorly, and first supralabial ventrally; frontonasals paired, rugose, nearly rectangular and twice as long as wide, with posterior edges forming an obtuse angle, in contact with internasal anteriorly, pre-supraocular scales and frontal posteriorly, and nasal and frenocular ventrally; frontal single, rugose, subpentagonal, wider than long, in contact with frontonasals anteriorly, pre-supraocular scales and first supraocular scales laterally, and frontoparietals posteriorly; supraoculars three; first supraocular larger than others, in contact with frontal and pre-supraocular scales anteriorly, frontoparietal medially, supercilliaries laterally, and second supraoccipital posteriorly; lower eyelid with unpigmented palpebral disc divided into three large scales; frenocular large, rectangular, about twice as long as tall, in contact with nasal anteriorly, frontonasal dorsally, lorilabial ventrally, preoculars and first pre-supraocular posteriorly; lorilabial in contact with nasal anteriorly, first and second supralabials ventrally, frenocular and preoculars dorsally, and first subocular posteriorly; suboculars in 2-5 longitudinal rows, of which the ventralmost contains five enlarged scales in contact with supralabials III-V; frontoparietals two, similar in size to frontal when combined, contacting frontal anteriorly, first and second supraocular laterally, and scales of parietal region posteriorly; parietal region covered with small irregular scales; one pair of spine-like temporals on each side; supralabials five; infralabials four; mental longer than wide, in contact with postmental posteriorly and first infralabials laterally; postmental trapezoidal, in contact with first infralabials laterally and one pair of chin shields and two small lateral scales posteriorly; chin shields in one pair, about twice as long as wide, separated from infralabials by small scales; gular region with five transverse rows of 5-7 large spiny scales that extend to lower part of tympanum.

Dorsum with a vertebral row of paired, enlarged, keeled scales, and two paravertebral series of short oblique rows of projecting scales, with scales increasing in size posteriorly on each row so that the most posterior scale forms a greatly enlarged, projecting spine; scales between vertebral row and paravertebral series of short rows heterogeneous in size, with enlarged scales forming 
281

282

283

284

285

286

287

288

289

290

291

292

293

294

295

296

297

298

299

300

301

302

303

304

305

306

307

308

309

310

311

312

313

314

315

316

317

318

319

oblique rows that converge medially to form chevrons; body flanks with seven oblique rows of spine-like scales, which are separated from each other by small, irregular, tubercular scales; ventral scales keeled, with rounded edges and in four longitudinal rows on pectoral region, but squared and in eight longitudinal rows on belly.

Limbs pentadactyl; digits clawed; subdigital lamellae on fourth finger single (second subdigital on left side divided), 16 on left side and 14 on right side; subdigital lamellae on fourth toe 24 on both sides; dorsal surface of tail with two longitudinal rows of enlarged keeled scales in five to six pairs per caudal segment, increasing in size posteriorly on each segment; caudal longitudinal rows separated from each other by 3-7 small scales; four pairs of subcaudals per autotomic segment on anterior third of tail; three pairs of subcaudals per autotomic segment on posterior two thirds.

Coloration of holotype in life (Fig. 6A). The holotype has a dark brown dorsal background with creamy orange paravertebral blotches extending onto anterior end of tail; flanks with grayish cream circular marks; parietal region brown orange; temporal region and posterior border of mandible with scattered white scales; tip of snout with creamy orange marks; first supraocular with diagonal grayish cream line; supercilliaries with 2-3 pale marks; supralabials with a pair of grayish cream bars; nuchal spines intense orange; some spines along paravertebral rows creamy orange; dorsally, the base of the tail with a pair of pale orange blotches; venter gray, marmorated with black and dark brown; femoral pores yellowish cream; round, cream blotch on supra-anal region; limbs dark brown with grayish cream marks; iris copper red.

Coloration of holotype after 1-5 years in preservative (Figs. 2, 4, 5). The holotype is dorsally brown, with six pairs of paravertebral cream blotches; base of tail with broad transverse, yellowish cream bar; tip of snout with cream nasal and internasal scales; lips and chin with cream bands separated by black interspaces; ventral surface of body and limbs dark brown with cream marbling; femoral pores pale gray.

Measurements of the holotype (in mm). SVL $=69 \mathrm{~mm}$; TAL $=89.5 \mathrm{~mm}$; TRL $=33.6 \mathrm{~mm}$; SL $=13.7 \mathrm{~mm} ; \mathrm{HL}=20.1 \mathrm{~mm} ; \mathrm{HW}=13.2 \mathrm{~mm} ; \mathrm{HUM}=9.7 \mathrm{~mm} ; \mathrm{FAL}=9.1 \mathrm{~mm} ; \mathrm{HND}=9.3 \mathrm{~mm}$; $\mathrm{FEM}=12.5 \mathrm{~mm} ; \mathrm{TIB}=13.7 \mathrm{~mm} ; \mathrm{FTL}=15.7 \mathrm{~mm}$

Variation (Figs. 4, 5, 6). Intraspecific variation in morphometrics and lepidosis is presented in Tables 2 and 3. After 1-5 years in preservative (Figs. 4, 5), the paravertebral cream blotches of some male specimens are merged, sometimes forming continuous paravertebral stripes (DHMECN 15211); in females, both the paravertebral blotches and the dorsal transverse bar on base of tail are faint (DHMECN 14058) or absent (DHMECN 14060), whereas juveniles have a pair of light paravertebral stripes (DHMECN 14061) or a broad vertebral stripe along dorsum (DHMECN 12767, 14059), with a conspicuous dorsal transverse bar on base of tail. Regardless of sex or age, the snout (rostral, internasal and prefrontal scales) varies between cream, orange cream, and dark brown; gular background varies from dark brown to reddish brown; coloration 
320

321

322

323

324

325

326

327

328

329

330

331

332

333

334

335

336

337

338

339

340

341

342

343

344

345

346

347

348

349

350

351

352

353

354

355

356

357

358

359

360

of the belly can be predominantly dark brown. In life, the dorsal pale spots vary from yellowish cream to orange cream (Fig. 6).

Hemipenes (Fig. 7). The lobes of the expanded, heart-shaped right hemipenis, are not fully everted; it is $9.2 \mathrm{~mm}$ long and $8.7 \mathrm{~mm}$ wide. It has a globular hemipenial body, thinner at the base and broader distally, and bears two small symmetrical lobes. The sulcus spermaticus is defined by two thick parallel margins and extends medially in a straight line along the hemipenial body up to the lobular crotch, where a fleshy fold divides it into two branches that run medially on each lobe. Five short, oblique, and parallel flounces bearing five to seven calcified spicules each lie on each side of the sulcus spermaticus with a narrow nude area in between. Lateral and asulcate aspects of hemipenis are ornamented distally with eight approximately equidistant flounces bearing rows of calcified spicules; of these, the five distal flounces converge on the asulcate face forming chevrons with apices directed toward base of hemipenis, while the other three flounces increasingly diverge toward base of organ. On the asulcate side, these flounces are separated medially by a large naked region. Ventral to the flounces, the lateral and asulcate sides of the hemipenial body are covered by 41 large, evenly distributed spines that increase slightly in size towards the base of the organ.

Cranial Osteology (Figs. 8, 9, 10). The following description of the skull of Echinosaura fischerorum sp. nov. is based on female paratype DHMECN 15210. The skull is robust, moderately compressed (skull width $=60 \%$ of skull length) and moderately high (skull height $=$ $43 \%$ of skull length). The widest region of the skull is at the level of the contact between squamosal and jugal. The dorsal margin of the snout in lateral view is slightly convex. The surface of frontal and parietal is very rugose. Basioccipital, compound otooccipitals (fused opisthotic and exoccipital), prootics and supraoccipital are almost indistinguishably fused and the parabasisphenoid is partly fused to this structure. The mandibles are very robust, and coronoid, splenial and angular are largely fused with the compound bone. Intraspecific variation in cranial osteology of Echinosaura fischerorum sp. nov. is presented in Figs. S1 and S2.

\section{Dermatocranium}

Premaxilla (Figs. 8, 9A). The premaxilla bears 12 tooth loci. The ascending nasal process of the premaxilla contacts the nasals posteriorly and forms the anterior and the anterodorsal edge of the naris laterally. There is a small foramen anterolaterally on both sides of the premaxilla. The palatal shelf of the premaxilla is notched medially and contacts the premaxillary process of the maxilla.

Maxilla (Figs. 8, 9A). The maxilla bears 18 tooth loci, arranged in a straight row. The bone is large and occupies most of the lateral surface of the skull anterior and ventral to the orbit. The anterolateral process of the maxilla is slightly notched anteriorly and articulates with the maxillary process of the premaxilla. The facial process of the maxilla is triangular and forms the posterior edge of the naris. It contacts the nasal and the frontal dorsally, and the prefrontal 
361

362

363

364

365

366

367

368

369

370

371

372

373

374

375

376

377

378

379

380

381

382

383

384

385

386

387

388

389

390

391

392

393

394

395

396

397

398

399

400

posterodorsally, extensively overlapping the anterior process of the prefrontal. There is a row of five foramina on the supralabial edge of the facial process. The posterolateral process of the maxilla is posteriorly bifurcate and articulates with the jugal. The anteromedial process of the maxilla is elongate, triangular, and contacts the palatal shelf of the premaxilla laterally and the vomer medially, which represents the only contact point between the maxilla and the vomer. The medial edge of the palatal shelf of the maxilla is irregularly shaped and broadest at the level of maxillary teeth 7-10, tapering abruptly posterior to tooth 10 and ending at the level of tooth 14 . It forms a palatine facet, where the palatine articulates at the level of maxillary teeth 11-13. The posteromedial process of the maxilla articulates with the maxillary process of the ectopterygoid.

Nasal (Figs. 8A, C, 9A). The nasal is ellipsoid in dorsal view, much longer than wide and about twice as long as the premaxilla. Along the anterior half of the nasal its lateral edge articulates with the dorsal edge of the naris and along its posterior half it contacts the facial process of the maxilla laterally. Anteriorly the nasal is convexly shaped and in broad contact with the premaxilla. Both nasals are in broad contact medially. Posteriorly the nasal is in broad contact with the frontal.

Frontal (Figs. 8, 9). The anterior margin of the frontal is less than half the width of its posterior edge. The interorbital constriction is distinctly narrower than the anterior edge and at its narrowest point about one fourth the width of the posterior edge. The anterior margin has three pointed processes in dorsal view, of which the lateral two are slightly longer than the medial process. The nasal facets of the frontal are between the medial process and the lateral processes. The lateral process of the anterior margin contacts the dorsal edge of the facial process of the maxilla. The lateral margin of the frontal contacts the posterodorsal process of the prefrontal anteriorly and the anterior half of the dorsal edge of the postfrontal posteriorly. The median part of the frontal (posterior to the contact zone with the prefrontal and anterior to the contact zone with the postfrontal) is part of the dorsal margin of the orbit. The posterior edge of the frontal has a pair of short frontoparietal tabs (Roscito \& Rodrigues, 2010) that project slightly and articulate with the frontal facets of the parietal. The cristae cranii originate on the ventrolateral surface of the frontal and meet each other at midline, where they are fused into a tubular structure that extends posteriorly almost to the level where the anterior tip of the postfrontal contacts the frontal. This structure encapsulates the olfactory tract and reaches anteriorly to the level of the nasals. The anterolateral border of the cristae cranii contacts the medial edge of the prefrontal.

Parietal (Figs. 8, 9). The parietal is about as long as wide. It is distinctly shorter than the frontal and its widest part is narrower than the posterior end of the frontal. The anterolateral and the posterolateral processes of the parietal taper distally and are oriented outwards. The anterolateral process extends into the suture between the frontal and the postfrontal, which is the only contact zone between the parietal and postfrontal. The posterolateral process contacts the supratemporal and the squamosal posterolaterally, and the paroccipital process of the otoccipital posteriorly. 
401 The posterior edge of the parietal bears a posteromedial notch. The lateral margin of the parietal

402

403

404

405

406

407

408

409

410

411

412

413

414

415

416

417

418

419

420

421

422

423

424

425

426

427

428

429

430

431

432

433

434

435

436

437

438

439 posterior to the anterolateral process forms the dorsal margin of the supratemporal fenestra. A slender post-temporal fenestra is present, delimited anteriorly by the posterior margin of the parietal, and posteriorly by the supraoccipital, separated at the midline by a short anterior projection of the supraoccipital. On the ventral side of the parietal, a triangular descending process originates anterolaterally just posterior to the anterolateral process; the triangular process lies medial to the epipterygoid and reaches its dorsal tip without contact. The descending process lies slighty anterior to the alar process of the prootic.

Prefrontal (Fig. 8A, C). The prefrontal forms the anterior and anterodorsal margins of the orbit. The orbitonasal flange of the prefrontal contacts medially the anterolateral surface of the cristae cranii of the frontal and the anterior border of the palatine. A lacrimal foramen is present between the internal wall of the facial process of the maxilla and the ventral process of the prefrontal that rests half on the maxillary palatal shelf and half of the palatine. The ventral process of the prefrontral is broadly separated from the anterior process of the jugal. The posterodorsal process of the prefrontal is placed beneath the lateral margin of the frontal and is, thus, not visible in dorsal view.

Postfrontal (Figs. 8, 9). The postfrontal is triradiate and forms part of the posterodorsal margin of the orbit, contacting dorsally the posterior part of the frontal and the anterior part of the parietal. The ventral process of the postfrontal contacts the jugal ventrally, forming the postorbital bar and excluding the postorbital from the orbit. Laterally, the postfrontal contacts the postorbital. The posterodorsal process of the postfrontal comprises more than half the total length of the postfrontal and expands posteriorly to form part of the anterior border of the supratemporal fenestra. The acute anterior process of the postfrontal is triangular, projecting anteromedially, and corresponds to two-thirds of the length of the posterodorsal process.

Postorbital (Figs. 8, 9). The postorbital is long and lozenge-shaped. Anteriorly and along the anterior half of its dorsal margin it contacts the postfrontal. The posterior half of its dorsal margin forms the lateral border of the supratemporal fenestra. It contacts the dorsal surface of the anterior half of the squamosal posteriorly.

Squamosal (Figs. 8, 9). The squamosal is long and has a hockey-stick shape. The anterior twothirds are straight and taper into an acute tip, contacting the postorbital dorsally and the posterodorsal ending of the jugal laterally. The posterior part curves downwards to meet the supratemporal medially. The posteroventral tip fits into the deep notch of the tympanic crest of the quadrate. The squamosal forms the posterolateral border of the supratemporal fenestra and the posterodorsal border of the infratemporal fenestra. 
440 Epipterygoid (Figs. 8C, 9A). The epipterygoid is a rod-like slender bone with slightly expanded

441

442

443

444

445

446

447

448

449

450

451

452

453

454

455

456

457

458

459

460

461

462

463

464

465

466

467

468

469

470

471

472

473

474

475

476

477

478

479

epiphyses. The ventral epiphysis inserts into the fossa columellae of the pterygoid, and the dorsal epiphysis is located anterior to the alar process of the prootic and lateral to the descending process of the parietal, but not contacting these elements.

Supratemporal (Figs. 8A, C, 9B). The supratemporal is a small, rod-like slender bone which contacts the posterolateral process of the parietal dorsally, the squamosal laterally, the paroccipital process of the otoccipital medially, and the quadrate ventrally.

Quadrate (Figs. 8, 9). The quadrate is robust and conchal-shaped. It can be divided into a ventrally located mandibular condyle, articulating with the compound bone of the mandible, and a dorsally located cephalic condyle articulating with the supratemporal, the paroccipital process of the prootic and the ventral tip of the squamosal, which fits into a deep notch in the dorsal surface of the quadrate. A lateral concave tympanic crest, a posterior crest and a medial crest extend between the mandibular and cephalic condyles.

Jugal (Figs. 8, 9). The jugal is sigmoidal in shape. It forms part of the ventral and the posterior margins of the orbit. Anteriorly it is bifurcated with a longer pointed suborbital process and a shorter more rounded maxillary process. The robust dorsal temporal process contacts the ventral margin of the postfrontal, the postorbital and the anterior process of the squamosal, where it ends in a blunt tip. Medially, the jugal has a triangular ectopterygoid process, which contacts the lateral margin of the ectopterygoid. On its lower edge the jugal has a long and robust triangular free posterior process.

Vomer (Fig. 8B). The elongate vomer is the most anterior component of the skull floor located posterior to the premaxillary palatal shelf and attached to a cavity in it. The anterior process tapers to a pointed tip. The lateral shelf of the vomer has an irregular border that partly overlaps the palatal shelf of the maxilla dorsally. There is an anterolateral process that overlaps the vomeronasal fenestrae without contacting the maxillary palatal shelf. Posteriorly, the slender palatine process of the vomer overlaps ventrally the vomerine process of the palatine. The dorsal surface of the vomer has a curved transversal crest that contacts the septomaxilla. Posterior to the crest is a large vomerine foramen. There is a dorsal crest along the medial border of the vomer, which contacts its counterpart on the other vomer.

Palatine (Fig. 8). The palatine forms the middle portion of the skull floor. It is anteriorly wider and narrows posteriorly to meet the pterygoid. Anteromedially, the vomerine process overlaps the posterior end of the vomer. Anterolaterally, the wide maxillary process of the palatine articulates with the maxillary palatal shelf. Between the medial and lateral extremities of its anterior margin the palatine has a ventral concave surface, deeper anteriorly and gradually shallower posteriorly, which forms the choanal channel. Posteriorly, the pterygoid process

Peer) reviewing PDF | (2021:08:65159:1:1:NEW 18 Oct 2021) 
480

481

482

483

484

485

486

487

488

489

490

491

492

493

494

495

496

497

498

499

500

501

502

503

504

505

506

507

508

509

510

511

512

513

514

515

516

517

518

overlaps dorsally the medial palatine process of the pterygoid. The lateral margin of the posterior part of the palatine forms the medial margin of the suborbital fenestra.

Pterygoid (Figs. 8, 9). The Y-shaped pterygoid forms the posterior part of the skull floor. Anteriorly, the pterygoid is divided into a medial lanceolate palatine process and a lateral triangular and broad ectopterygoid process, forming the posterior margin of the suborbital fenestra. The palatine process overlaps with the pterygoid process of the palatine. The ectopterygoid process fits into a facet between the dorsal and ventral portions of the posteromedial process of the ectopterygoid. Posteriorly, the long and slender quadrate process extends dorsolaterally to almost reach, but not contact the medial crest of the quadrate. The basipterygoid process of the parabasisphenoid contacts the pterygoid medially at about midlength. The dorsomedial surface of the pterygoid has a shallow groove, the fossa columellae, into which the ventral epiphysis of the epipterygoid inserts.

Ectopterygoid (Fig. 8B, C). The ectopterygoid is a short but robust bone that forms part of the posterior and external margin of the suborbital fenestra. Anteriorly, its maxillary process articulates with the posteromedial process of the maxilla. Laterally, it contacts the triangular ectopterygoid process of the jugal. Posteriorly, the posteromedial process of the ectopterygoid articulates with the ectopterygoid process of the pterygoid.

Septomaxilla (Fig. 8C). The dome-shaped septomaxilla is located between the vomer and the premaxilla, and rests laterally on the palatal shelf of the maxilla. Dorsally it reaches close to the ventral side of the nasal process of the premaxilla but does not contact this process.

\section{Neurocranium}

Parabasisphenoid (Figs. 8B, C, 9B). The body of the parabasisphenoid is roughly rectangular and bears two long basipterygoid processes that project anterolaterally to meet the pterygoid medially. These processes are flattened near the facet of the pterygoid. Anteriorly, between the basipterygoid processes is a rectangular parasphenoid rostrum. The parabasisphenoid is partly fused to the prootic posterolaterally and to the basioccipital posteriorly.

Prootic (Figs. 8C, 9A). The prootic forms the anterior portion of the otic capsule. It has an anteriorly directed curved and compressed alar process, which approaches the descending process of the parietal and the epipterygoid but does not contact those structures. Below the alar process is the $\mathrm{C}$-shaped incisura prootica, a deep and round notch and exit for the trigeminal nerve. The posterior border of the prootic is marked by the fenestra ovalis, into which the rounded footplate of the stapes inserts. The crista prootica begins at the parabasisphenoid and runs across the lateral side of the prootic. Posterior to its tip and at about the same level as the trigeminal notch is the small foramen for the facial nerve. Dorsally, the prootic contacts the 
519 supraoccipital. Ventrally, it articulates with the parabasisphenoid anteromedially and with the

520 basioccipital posteromedially.

521

522 Otooccipital (Figs. 8A, C, 9B). The compound otooccipital (fused opisthotic and exoccipital)

523 forms the posterior portion of the otic capsule. It contributes to the composition of the occipital

524 condyle and forms the lateral margin of the foramen magnum. The otoocipital contacts the

525 supraoccipital dorsally and the basioccipital ventrally. Its anterior border contacts the prootic,

526 and has a C-shaped notch, which forms the posterior margin of the fenestra ovalis, and its

527 anterodorsal margin is thickened to form the paroccipital process. Posterolaterally to the fenestra

528 ovalis is the paroccipital process, which contacts the supratemporal and the quadrate laterally.

529 The sphenoccipital tubercle is situated at the junction of the otoccipital and the basioccipital.

530 This tubercle is ventral to the fenestra ovalis, and between both structures is an ellipsoid lateral

531 foramen.

532

533 Basioccipital (Figs. 8A, 9B). The pentagonal-shaped basioccipital forms most of the braincase

534 floor. Anteriorly, it is fused to the parabasisphenoid, dorsally it contacts the prootic (anterior) and

535 the otooccipital (posterior). It forms the ventral margin of the occipital condyle.

536

537 Supraoccipital (Figs. 8A, 9B). The hourglass-shaped broad supraoccipital forms the roof of

538 both the braincase and otic capsules. The short ascending process of the tectum synoticum

539 originating at the anterior margin of the supraoccipital does not reach the parietal bone. A large

540 posttemporal fenestra is present between the supratemporal and the parietal. The supraoccipital

541 articulates with the dorsal margin of the prootic anterolaterally and with the otooccipital

542 posterolaterally. The posterior border forms the dorsal edge of the foramen magnum.

543

544 Orbitosphenoid (Fig. 8B, C). The small paired orbitosphenoids are compressed and L-shaped with the vertex oriented laterally and bearing a small lateral process. The dorsal process is broad and both bones are completely fused medially along this process, forming a slightly bifurcate anterior end of the fused bone. On the ventral surface of the fused dorsal region is a short median, comparatively broad anteroventrally oriented process. The ventral processes of the fused orbitosphenoid bone are slender, directed medially, but distinctly separated. The orbitosphenoid is located anterior to the braincase and posterior and medially with respect to the orbits, at an angle to the dorsoventral axis of the skull.

552

Stapes (Figs. 8B, 9A). The ossified stapes is composed of a long and slender laterally projecting shaft and a large, rounded footplate, which entire fills the area of the fenestra ovalis. The shaft ends proximal to the posterior crest of the quadrate.

556

557

\section{Mandible}


558 Dentary (Figs. 9, 10). The dentary is the anterior part of the mandible and bears a straight row of 55922 (right) to 23 (left) teeth loci. Posteriorly, the dentary contacts the coronoid, angular, splenial 560 and surangular. The labial and anteromedial processes of the coronoid clasp the posterodorsal 561 surface of the dentary. Anteriorly, at the lingual surface of the dentary, the opening of Meckel's 562 canal is observed near the mandibular symphysis. The dentary has about five foramina, the 563 anteriormost two are located on the symphyseal region, and the posteriormost is at the level of 564 the midpoint of the dental row.

565

566 Coronoid (Figs. 9A, 10). The triradiate coronoid has a long and robust free dorsal coronoid

567

568

569

570

571

572

573

574

575

576

577

578

579

580

581

582

583

584

585

586

587

588

589

590

591

592

593

594

595

596

process. The labial process tapers anteriorly up to the level of the gap between the third and fourth posteriormost teeth of the dentary. On the lingual surface of the mandible, the anteromedial process of the coronoid contacts the dentary anteriorly, the splenial ventrally, and the surangular posteriorly. The slender posteromedial process contacts the surangular, but the exact borders are not well resolved in the CT-images. There is a small medial crest between the lower part of the coronoid process and the posteromedial process.

Angular (Figs. 9B, 10A, B, D). The small and slender angular has a pointed anterior and a blunt posterior end. It is located on the ventral surface of the mandible, ventral to the angular process of the dentary. It contacts the surangular posteriorly and the ventral border of the splenial medially. The posterior mylohyoid foramen is visible ventrally at the posterior end where the angular meets the surangular.

Splenial (Figs. 9B, 10A, B, D). The splenial forms the midventral portion of the lingual surface of the mandible. It contacts the dentary anteriorly, the coronoid dorsally, the angular ventrally, and the compound bone posterodorsally. There are two foramina present in the anterior region of the splenial: a larger oval anterior inferior foramen at the suture with the dentary, and a more rounded anterior mylohyoid foramen about half as large, located ventral and posterior to the anterior inferior foramen. The exact borders of the splenial are not well resolved in the CTimages, making it difficult to comment about the exact shape of the bone.

Mandibular Compound Bone (Figs. 9, 10). The compound bone is the posterior part of the mandible and is formed by the fusion of the surangular on the labial surface, and the prearticular and articular on the lingual surface of the mandible. The prearticular forms the floor and the internal margin of the adductor fossa, while the articular forms its posterior margin and provides the articulation to the skull on its dorsal surface. The surangular is located posterior to the dentary and the coronoid and a large surangular foramen is observed next to the contact with the coronoid. Ventral to the surangular is the angular. The retroarticular process is formed by the fused surangular and prearticular-articular complex.

PeerJ reviewing PDF | (2021:08:65159:1:1:NEW 18 Oct 2021) 
597 Vertebrae (Fig. 15, 16). There are two sacral vertebrae and 25 presacral vertebrae of which the 598 first three and the last one do not bear ribs.

599

600

601

602

603

604

605

606

607

608

609

610

611

612

613

614

615

616

617

618

619

620

621

622

623

624

625

626

627

628

629

630

631

632

633

634

635

Pectoral Girdle (Fig. 15, 16). The pectoral girdle consists of a clavicle, suprascapular, interclavicle, fused scapula and coracoid, epicoracoid, sternum, and xiphisternum. The clavicle is large, triangular, flattened, and encloses a large fenestra. The anterior part of the interclavicle is trifurcate with one median and two anterolaterally oriented processes, each of them about onefourth the total length of the interclavicle and tapering anteriorly. The median process penetrates anteriorly the posterior third of the suture between the two clavicles. Posteriorly, it has a long, straight, rod-like and posteriorly tapering branch, which surpasses the central part of the sternal fontanelle. The large scapulocoracoid bears a small coracoid fenestra, a large anterior coracoid fenestra, a medium-sized posterior coracoid fenestra, a large scapulocoracoid fenestra, and the glenoid fossa. The rhomboid sternum has a large central fontanelle and is associated with three pairs of sternal ribs. The rod-like xiphisternum has two fenestrae and receives two pairs of xiphisternal ribs. The suprascapula is not visible in ventral view and contacts the scapulocoracoid and the clavicle laterally. The epicoracoid contacts the median edge of the coracoid, but most of this structure is overlain by the interclavicle.

Distribution and Natural History (Figs. 16, 17). Echinosaura fischerorum sp. nov. is known from the western slopes of the Andes in northwestern Ecuador, Imbabura and Carchi Provinces, between 1,495-1,750 m (Fig. 17). All known specimen records lie in the lower montane forest ecosystem of the Mira river basin within the Dracula Reserve, a 1,136 ha private protected area managed by the Ecominga foundation. The record from Imbabura province corresponds to a photograph by Jaime Culebras from Manduriacu Reserve of Fundación Ecominga. Most known localities of E. fischerorum sp. nov. are in close proximity to the Ecuador-Colombia border and we expect that this species might also be present in neighboring Colombia. Most specimens were observed active among tree roots during the day and collected in pitfall traps along forest ridges near streams. Gravid females were collected in April and November. One female paratype (DHMECN 15210) contained two large oval eggs in the oviduct and several snail shells in the stomach (Fig. 16).

Etymology. The specific epithet is a patronym in honor of Beat Fischer and Urs Fischer, donors who have contributed significantly to the consolidation of the Dracula Reserve in the sectors of Peñas Blancas and El Pailón, which not only protect the populations of this new endemic species, but also important populations of threatened amphibians and reptiles of the Mira river basin.

\section{Discussion}


636 Vásquez-Restrepo et al. (2020) presented an extensive review of Echinosaura based on 637 molecular phylogeny, external morphology and biogeography. However, no material was 638 available to those authors for review from extreme southwestern Colombia and northwestern 639 Ecuador, that would have offered the possibility of recognizing additional candidate species of 640 Echinosaura.

641

642 The new species is genetically distinct from its congeners and is readily distinguishable based on 643 external morphological characters. By contrast, information on internal morphology of 644 Echinosaura is very scarce and to date only few studies (Bell, Evans \& Maisano, 2003; Estes, de 645 Queiroz \& Gauthier, 1988; Evans, 2008; MacLean, 1974) have been published with exemplary 646 information on cranial morphology of Echinosaura. Furthermore, this information is based only 647 on one specimen of E. panamensis (CAS 99994) and two specimens of E. horrida (MCZ 18858, 648 USNM 163424) (Bell, Evans \& Maisano, 2003; Evans, 2008). Here, for the first time a detailed 649 description of the cranial morphology of Echinosaura is provided based on CT data of a paratype 650 (DHMECN 15210) of the new species herein described. Unlike E. horrida and E. panamensis, 651 the nasal bones of E. fischerorum sp. nov. are not separated and thus the premaxilla does not 652 meet the frontal. The postfrontal is not excluded from the upper temporal fenestra as indicated by 653 Evans (2008) for E. horrida, but rather expands posteriorly to form the anterior border of the 654 fenestra. Although information on skull morphology of Echinosaura is scarce, our data show 655 remarkable interspecific variation suggesting that skull morphological characteristics have 656 taxonomic value. Future studies should therefore examine and compare the skulls of other 657 species of Echinosaura to obtain a better overall picture of the skull of the genus. In addition, to 658 estimate the degree of intraspecific variation and thus avoid misinterpretation at the species level, 659 several individuals per species should be examined. Due to possible cryptic diversity within 660 widespread linages, it is also advisable to include type material in the analyses, if possible, in 661 order to be able to make reliable statements about the cranial osteology of the individual species.

662

663 The recognition of Echinosaura fischerorum sp. nov. improved our understanding of the 664 diversity and evolutionary history of Echinosaura. However, we acknowledge that further 665 phylogenetic and phylogeographic analyses of the populations assigned to Echinosaura 666 fischerorum sp. nov. from the Río Manduriacu Reserve are needed.

667 The new species described in this paper occurs in a particular area of high endemism and 668 biological diversification in extreme northwestern Ecuador. Therefore, we expect its occurrence 669 in the neighboring country of Colombia, a distribution pattern observed in other species of small 670 vertebrates (Arteaga et al., 2016; Yánez-Muñoz et al., 2018; Brito et al., 2020; Reyes-Puig et al. 671 2020).

672 In terms of conservation, although the type locality of Echinosaura fischerorum sp. nov. is part 673 of the ecological reserves managed by the Ecomiga Foundation, the entire area is threatened by 674 human impacts such as mining concessions and land use changes for logging. The IUCN 
675

676

677

678

679

680

681

682

683

684

685

686

687

688

689

690

691

692

693

694

695

696

697

698

699

700

701

702

703

704

705

706

707

708

709

710

711

712

713

714

conservation status of this new species should be evaluated as soon as possible in further studies, as it is very likely to be threatened.

\section{Conclusions}

Fieldwork in the western foothills of the Andes in northwestern Ecuador led us to the discovery of a new species of Echinosaura and increased the number of known species of this genus to eight.

Our phylogenetic analyses support the monophyly of Echinosaura fischerorum sp. nov. While its sister species $E$. horrida is relatively widespread in the tropical lowland rainforest of western Ecuador, the record of E. fischerorum sp nov. from Manduriacu suggests that this species is most likely widespread between Manduriacu Reserve and Río Mira.

\section{Acknowledgements}

We want to express our gratitude to the Rainforest Trust and their "Species Legacy" program, to Orchid Conservation Alliance, and University of Basel for their support of EcoMinga

Foundation's efforts to protect the forest where the new species was discovered. Special thanks to Javier Robayo, Lou Jost, Beat Fischer and Urs Fischer for their continuous support since the beginning of Dracula Reserve. We appreciate the institutional support given by Diego Inclan and Francisco Prieto of INABIO. We thank the collaboration during field work by Callie Broadus, Jaqui Curay, Rocío Manovandas, Rubí García, Jorge Brito, Glenda Pozo, Jordi Salazar, Fausto Recalde, Mateo A. Vega-Yánez, Gabriela Puetate, Pearson McGovern, Natalia Espinoza, Daniel Valencia, Marco Montero, Andy Better, Julio Carrión, Mauricio Herrera-Madrid, Roberto Taicus and the "Dracula's Rangers" of Ecominga Foundation: Hector Yela, Milton Canticuz, Jeovany Guerra, Rolando Peña, Nilo Ortiz, and David Yela. The work of MYM and JRP is part of the research program Diversidad de Pequeños Vertebrados de Ecuador, supported by INABIO through the project: "Conservación de la Biodiversidad en la Cuenca Binacional de los Ríos Mira-Mataje (MMRB): Construcción de Bases Biofísicas y Socio-ambientales para la Conservación y el Manejo Adaptativo de Servicios Ecosistémicos". Ministerio de Ambiente de Ecuador issued research permits and framework agreement for access to genetic resources. We are grateful to Patrick Campbell (BMNH), Andreas Schmitz (MHNG), Silke Schweiger and Georg Gassner (NMW) for loan of specimens and to Morris Flecks (ZFMK) for taking photographs. Chris Phillips (UIMNH) kindly sent us photographs of the holo- and paratype of $E$. keyi. The "Germany-Brazil-Ecuador Trilateral Cooperation Program" of the GIZ international cooperation provided financial support to MYM and CK. OTC was financially supported by the Deutscher Akademischer Austauschdienst (DAAD). Laboratory work was funded by a grant from SENESCYT (Arca de Noé Initiative; S. R. Ron and O. Torres-Carvajal principal investigators). 
715 APPENDIX. Specimens examined.

$716 *$ Type specimens

717

718

719

Echinosaura fischerorum sp. nov. (n=9): ECUADOR: Carchi: Reserva Dracula, Sector El Guapilal:

720

DHMECN 15208*, DHMECN 15209*, DHMECN 15210*, DHMECN 15211*; Reserva Dracula, Sector

721

El Pailón Chico: DHMECN 14058*, DHMECN 14059*, DHMECN 14060*, DHMECN 14061*; Reserva

721

Dracula, Cerro Oscuro: DHMECN 12767*.

722 Echinosaura brachycephala $(\mathrm{n}=7)$ : ECUADOR: Cotopaxi: Las Pampas (= San Francisco de las

723 Pampas, -0.418, -78.966, 1,275 m elevation): MHNG 2359.39, ZFMK 46370*, ZFMK 46371*,

724 ZFMK 46372*; Pichincha: Santa Lucía Cloudforest Ecological Reserve (0.0922, -78.620, 1800

725 m): QCAZ 11913, QCAZ 11918; Santa Lucía Cloudforest Ecological Reserve, Gallo de la Peña

726 trail $(0.117,-78.607,1,932 \mathrm{~m})$ : QCAZ 10824.

727 Echinosaura horrida $(\mathrm{n}=6)$ : ECUADOR: ZFMK 7272; Pacific versant of Ecuador: ZFMK

728 43762, ZFMK 43763, ZFMK 46369; Esmeraldas: Tesoro Escondido Reserve (0.4969600, -

729 79.13682, 620 m): QCAZ 15030; Manabí: Zapote (-0.375, -79.605, 154 m): QCAZ 14506.

730 Echinosaura keyi $(\mathrm{n}=2)$ : ECUADOR: ZFMK 76379; Pichincha: E Rio Baba bridge, $24 \mathrm{~km} \mathrm{~S}$

731 Santo Domingo de los Colorados, 600 m: UIMNH 80541*.

732 Echinosaura orcesi $(\mathrm{n}=4)$ : ECUADOR: Esmeraldas: road Alto Tambo - El Placer (0.9, -78.616,

733585 m): QCAZ 6299; Tesoro Escondido Reserve, Camarón river (0.544, -79.142, 243 m): QCAZ

734 15026; Carchi: San Marcos, 670 m: NMW 32000:1*; San Marcos, 700 m: NMW 32000:2*.

735 Echinosaura palmeri $(\mathrm{n}=1)$ : COLOMBIA: Chocó: Noananoá, Río San Juan, 30 m: BMNH

736 1923.10.12.14.

737 Echinosaura panamensis $(\mathrm{n}=7)$ : PANAMA: Coclé: 5-6 km N El Copé: ZFMK 45779, ZFMK

738 50084, ZFMK 50085, ZFMK 50462, ZFMK 50464, ZFMK 52200, ZFMK 54631.

739

740

741

742

743

744

745

746

\section{References}

Arteaga A, Pyron RA, Peñafiel N, Romero-Barreto P, Culebras J, Bustamante L, Yánez-Muñoz M, Guayasamin JM. 2016. Comparative phylogeography reveals cryptic diversity and repeated patterns of cladogenesis for amphibians and reptiles in Northwestern Ecuador. PloS One 11(4):e0151746. https://doi.org/10.1371/journal.pone.0151746 
747

748

749

750

751

752

753

754

755

756

757

758

759

760

761

762

763

764

765

766

767

768

769

770

771

772

773

774

775

776

777

778

779

780

781

782

783

784

785

786

787

788

789

790

791

Beaupre SJ, Jacobson ER, Lillywhite HB, Zamudio K. 2004. Guidelines for use of live amphibians and reptiles in field and laboratory research. Lawrence, Kansas: American Society of Ichthyologists and Herpetologists.

Bell CJ, Evans S, Maisano JA. 2003. The skull of the gymnophthalmid lizard Neusticurus ecpleopus (Reptilia: Squamata). Zoological Journal of the Linnean Society 139(2):283-304. https://doi.org/10.1046/j.1096-3642.2003.00077.x

Brito J, Koch C, Percequillo AR, Tinoco N, Weksler M, Pinto CM, Pardiñas UF. 2020. A new genus of oryzomyine rodent (Cricetidae, Sigmodontinae) with three new species from montane cloud forests, western Andean cordillera of Colombia and Ecuador. PeerJ 8:e10247. https://doi.org/10.7717/peerj.10247

Castoe TA, Doan TM, Parkinson CL. 2004. Data partitions and complex models in Bayesian analysis: The phylogeny of gymnophthalmid lizards. Systematic Biology 53(3):448-469. https://doi.org/10.1080/10635150490445797

de Queiroz K. 2007. Species concepts and species delimitation. Systematic Biology 56(6):879-886. https://doi.org/10.1080/10635150701701083

Deng W, Maust BS, Nickle DC, Learn GH, Liu Y, Heath L, Kosakovsky Pond SL, Mullins JI. 2010. DIVEIN: a web server to analyze phylogenies, sequence divergence, diversity, and informative sites. BioTechniques 48:405-408. doi 10.2144/000113370

Estes R, de Queiroz K, Gauthier J. 1988. Phylogenetic relationships within Squamata. In: Estes R, Pregill G, eds. Phylogenetic relationships of the lizard families. Stanford, California: Stanford University Press, 119-128.

Evans SE. 2008. The skull of lizards and tuatara. In: Gans C, Gaunt AS, Adler K, eds. Biology of the Reptilia, Vol. 20 Morphology H: the Skull of Lepidosauria. Ithaca, NY: Society for the Study of Amphibians and Reptiles, 1-347.

Fitzgerald LA. 2012. Finding and capturing reptiles. In: McDiarmid RW, Foster MS, Guyer C, Gibbons JW, Chernoff N, eds. Reptile Biodiversity: Standard Methods for Inventory and Monitoring. Oakland, California: University of California Press, 77-88.

Fritts TH, Almendáriz A, Samec S. 2002. A new species of Echinosaura (Gymnophthalmidae) from Ecuador and Colombia with comments on other members of the genus and Teuchocercus keyi. Journal of Herpetology 36(3):349-355. 10.1670/00221511(2002)036[0349:ANSOEG]2.0.CO;2

Goicoechea N, Frost DR, De la Riva I, Pellegrino KCM, Sites Jr J, Rodrigues MT, Padial JM. 2016. Molecular systematics of teioid lizards (Teioidea/Gymnophthalmoidea: Squamata) based on the analysis of 48 loci under tree-alignment and similarity-alignment. Cladistics 32(6):624-671. https://doi.org/10.1111/cla.12150

Guindon S, Dufayard JF, Lefort V, Anisimova M, Hordijk W, Gascuel O. 2010. New algorithms and methods to estimate maximum-likelihood phylogenies: assessing the performance of PhyML 3.0. Systematic Biology 59(3):307-321. https://doi.org/10.1093/sysbio/syq010

Hernández Morales C, Peloso PLV, Bolívar García W, Daza JD. 2019. Skull Morphology of the Lizard Ptychoglossus vallensis (Squamata: Alopoglossidae) With Comments on the Variation Within Gymnophthalmoidea. The Anatomical Record 302:1074-1092. https://doi.org/10.1002/ar.24038

Jerez A, Tarazona OA. 2009. Appendicular skeleton in Bachia bicolor (Squamata: Gymnophthalmidae): osteology, limb reduction and postnatal skeletal ontogeny. Acta Zoologica 90(1):42-50. https://doi.org/10.1111/j.1463-6395.2008.00331.x 
792

793

794

795

796

797

798

799

800

801

802

803

804

805

806

807

808

809

810

811

812

813

814

815

816

817

818

819

820

821

822

823

824

825

826

827

828

829

830

831

832

833

834

835

836

Katoh K, Standley DM. 2013. MAFFT multiple sequence alignment software version 7: improvements in performance and usability. Molecular Biology and Evolution30(4):772-780. https://doi.org/10.1093/molbev/mst010

Köhler G, Böhme W, Schmitz A. 2004. A New Species of Echinosaura (Squamata: Gymnophthalmidae) from Ecuador. Journal of Herpetology 38(1):52-60. https://doi.org/10.1670/164-02A

Lanfear R, Calcott B, Ho SYW, Guindon S. 2012. Partition-Finder: Combined selection of partitioning schemes and substitution models for phylogenetic analyses. Molecular Biology and Evolution 29(6):1695-1701. https://doi.org/10.1093/molbev/mss020

Lanfear R, Frandsen PB, Wright AM, Senfeld T, Calcott B. 2017. PartitionFinder 2: New Methods for Selecting Partitioned Models of Evolution for Molecular and Morphological Phylogenetic Analyses. Molecular Biology and Evolution 34(3):772-773. https://doi.org/10.1093/molbev/msw260

MacLean WP. 1974. Feeding and locomotor mechanism of teiid lizards: Functional morphology and evolution. Papéis Avulsos de Zoologia 27:179-213.

Marques-Souza S, Prates I, Fouquet A, Camacho A, Kok PJR, Nunes PMS, Dal Vechio F, Sousa Recoder R, Mejia N, Teixeira Junior V, Barrio-Amorós C, Cassimiro J, Dias Lima J, de Sena MA, Rodrigues MT. 2018. Reconquering the water: Evolution and systematics of South and Central American aquatic lizards (Gymnophthalmidae). Zoologica Scripta 47(3):255-265. https://doi.org/10.1111/zsc.12273

Miller M, Pfeiffer W, Schwartz T. 2010. Creating the CIPRES Science Gateway for 1100 inference of large phylogenetic trees. In: Gateway Computing Environments 1101 Workshop (GCE). IEEE, 1-8.

Nunes PMS, Fouquet A, Curcio FF, Kok PJR, Rodrigues MT. 2012. Cryptic species in Iphisa elegans Gray, 1851 (Squamata: Gymnophthalmidae) revealed by hemipenial morphology and molecular data. Zoological Journal of the Linnean Society 166:361-376. https://doi.org/10.1111/j.1096-3642.2012.00846.x

Pellegrino KCM, Rodrigues MT, Yonenaga-Yassuda Y, Sites JW. 2001. A molecular perspective on the evolution of microteiid lizards (Squamata, Gymnophthalmidae), and a new classification for the family. Biological Journal of the Linnean Society 74(3):315338. https://doi.org/10.1006/bij1.2001.0580

Rambaut A, Drummond AJ. 2016. TreeAnnotator version 1.8.3. Inc.

Reyes-Puig C, Wake D, Kotharambath R, Streicher J, Koch C, Cisneros-Heredia D, YánezMuñoz M, Ron S. 2020. Two extremely rare new species of fossorial salamanders of the genus Oedipina (Plethodontidae) from northwestern Ecuador. PeerJ 8:e9934 https://doi.org/10.7717/peerj.9934

Rodrigues MT, Teixeira Jr M, Dal Vechio F, Amaro RC, Nisa C, Guerrero AC, Damesco R, Roscito JG, Nunes PMS, Recorder RC. 2013. Rediscovery of the earless microteiid lizard Anotosaura collaris Amaral, 1933 (Squamata: Gymnophthalmidae): a redescription complemented by osteological, hemipenial, molecular, karyological, physiological and ecological data. Zootaxa 3731(3):345-370. https://doi.org/10.11646/zootaxa.3731.3.5

Ronquist F, Teslenko M, van der Mark P, Ayres DL, Darling A, Höhna S, Larget B, Liu L, Suchard MA, Huelsenbeck JP. 2012. MrBayes 3.2: Efficient Bayesian phylogenetic inference and model choice across a large model space. Systematic Biology 61:539-542. https://doi.org/10.1093/sysbio/sys029 
837

838

839

840

841

842

843

844

845

846

847

848

849

850

851

852

853

854

855

856

857

858

859

860

861

862

863

864

865

866

867

868

869

870

871

872

873
Roscito JG, Rodrigues MT. 2010. Comparative cranial osteology of fossorial lizards from the tribe gymnophthalmini (Squamata, Gymnophthalmidae). Journal of Morphology 271(11):1352-1365. https://doi.org/10.1002/jmor.10878

Savage JM. 1997. On terminology for the description of the hemipenis of squamate reptiles. Herpetological Journal 7:23-25.

Stamatakis A. 2014. RAxML Version 8: A tool for phylogenetic analysis and post-analysis of large phylogenies. Bioinformatics 30(9):1312-1313. https://doi.org/10.1093/bioinformatics/btu033

Stamatakis A, Hoover P, Rougemont J. 2008. A rapid bootstrap algorithm for the RAxML Web servers. Systematic Biology 57(5):758-771. https://doi.org/10.1080/10635150802429642

Torres-Carvajal O, Lobos SE, Venegas PJ, Chávez G, Aguirre-Peñafiel V, Zurita D, Echeverría L. 2016. Phylogeny and biogeography of the most diverse clade of South American gymnophthalmid lizards (Squamata, Gymnophthalmidae, Cercosaurinae). Molecular Phylogenetics and Evolution 99:63-75. https://doi.org/10.1016/j.ympev.2016.03.006

Torres-Carvajal O, Pazmiño-Otamendi G, Ayala-Varela F, Salazar-Valenzuela D. 2021. Reptiles del Ecuador. Version 2021.1. Museo de Zoología, Pontificia Universidad Católica del Ecuador. Available at https://bioweb.bio/faunaweb/reptiliaweb (accessed 02 July 2021).

Uzzell T. 1973. A revision of lizards of the genus Prionodactylus, with a new genus for $P$. leucostictus and notes on the genus Euspondylus (Sauria, Teiidae). Postilla 159:1-67.

Uzzell TM Jr. 1965. Teiid Lizards of the genus Echinosaura. Copeia 1965(1):82-89. https://doi.org/10.2307/1441244

Vásquez-Restrepo JD, Ibáñez R, Sánchez-Pacheco SJ, Daza JM. 2020. Phylogeny, taxonomy and distribution of the Neotropical lizard genus Echinosaura (Squamata: Gymnophthalmidae), with the recognition of two new genera in Cercosaurinae. Zoological Journal of the Linnean Society 189(1):287-314. https://doi.org/10.1093/zoolinnean/zlz124

Yánez-Muñoz M, Reyes-Puig C, Reyes-Puig J, Velasco J, Ayala-Varela F, Torres-Carvajal O. 2018. A new cryptic species of Anolis lizard from northwestern South America (Iguanidae, Dactyloinae). ZooKeys 794:135-163. https://doi.org/10.3897/zookeys.794.26936

Yánez-Muñoz MH, Batallas D, Franco-Mena D, Meza-Ramos PA, Oyagata LA, PadillaD, Paucar C, Reyes-Puig JP, Rodríguez A, Urgilés-Merchán MA, Vega-Yánez M. 2020. Anfibios en los Ecosistemas Andino-Tropicales de la provincia del Carchi. INABIOGADPC. 


\section{Table 1 (on next page)}

Variation in selected morphological characters of the different species of Echinosaura.

$\mathrm{n}=$ number of specimens studied; SVL = snout-vent length. 
Table 1. Variation in selected morphological characters of the different species of Echinosaura $. \mathrm{n}=$ number of specimens studied; $\mathrm{SVL}=\mathrm{snout}-$ 2 vent length.

\begin{tabular}{|c|c|c|c|c|c|c|c|c|}
\hline SPECIES & $\begin{array}{l}\text { E. } \\
\text { fischerorum } \\
\text { sp nov. }(\mathrm{n}=9)\end{array}$ & $\begin{array}{l}\begin{array}{l}\text { E. } \\
\text { brachycephala } \\
(\mathrm{n}=25)\end{array} \\
\end{array}$ & $\begin{array}{l}\text { E. centralis } \\
(\mathrm{n}=39)\end{array}$ & $\begin{array}{l}\text { E. horrida } \\
(\mathrm{n}=27)\end{array}$ & $\begin{array}{l}\text { E. keyi } \\
(\mathrm{n}=14)\end{array}$ & $\begin{array}{l}\text { E. orcesi } \\
(\mathrm{n}=4)\end{array}$ & $\begin{array}{l}\text { E. palmeri } \\
(\mathrm{n}=44)\end{array}$ & $\begin{array}{l}\text { E. panamensis } \\
(\mathrm{n}=10)\end{array}$ \\
\hline $\begin{array}{l}\text { Max. SVL } \\
\text { males (mm) }\end{array}$ & $69(n=3)$ & $72(\mathrm{n}=10)$ & 75 & $86(n=14)$ & $80(n=7)$ & $70(n=2)$ & 80 & $71(n=5)$ \\
\hline $\begin{array}{l}\text { Max. SVL } \\
\text { females (mm) }\end{array}$ & $67(n=9)$ & $78(n=15)$ & 77 & $80(n=13)$ & $64(n=7)$ & $81(n=2)$ & 74 & $74(n=5)$ \\
\hline Internasal & Single & Single & Divided & Single & Divided & Single & Divided & Divided \\
\hline Frontal & Single & Single & Single & Single & $\begin{array}{l}\text { Single (rarely } \\
\text { divided) }\end{array}$ & Single & Single & Divided \\
\hline $\begin{array}{l}\text { Subcaudals } \\
\text { per caudal } \\
\text { segment }\end{array}$ & 3 & 4 & 3 & 3 & 3 & $5-6$ & 3 & 3 \\
\hline Supralabials & $5-5$ & $3-5$ & $4-6$ & $4-6$ & $4-5$ & $3-5$ & $4-5$ & $4-6$ \\
\hline Infralabials & $4-4$ & 3 & $3-5$ & $3-4$ & $3-5$ & $2-3$ & $4-5$ & $4-6$ \\
\hline $\begin{array}{l}\text { Femoral } \\
\text { pores }\end{array}$ & $7-9$ & $7-9$ & $4-9$ & $7-10$ & $8-11$ & $5-15$ & $6-10$ & $3-9$ \\
\hline $\begin{array}{l}\text { Subdigital } \\
\text { lamellae on } \\
\text { 4th finger }\end{array}$ & $14-18$ & $14-23$ & $12-18$ & $14-19$ & $17(\mathrm{n}=1)$ & $20-22$ & $12-17$ & $13-16$ \\
\hline $\begin{array}{l}\text { Subdigital } \\
\text { lamellae on } \\
\text { 4th toe }\end{array}$ & $23-27$ & $23-32$ & $20-27$ & $21-25$ & $28(\mathrm{n}=1)$ & $30-36$ & $19-25$ & $20-22$ \\
\hline $\begin{array}{l}\text { Temporal and } \\
\text { nuchal scales }\end{array}$ & $\begin{array}{l}\text { A pair of sharp } \\
\text { spine like } \\
\text { scales in } \\
\text { temporal and } \\
\text { nuchal region }\end{array}$ & $\begin{array}{l}\text { Low rounded } \\
\text { tubercles } \\
\text { surrounded by } \\
\text { granular scales }\end{array}$ & $\begin{array}{l}\text { Temporal } \\
\text { region } \\
\text { tuberculated, } \\
\text { and nuchal } \\
\text { region with } \\
\text { two rows of } \\
\text { enlarged }\end{array}$ & $\begin{array}{l}\text { Low tubercles } \\
\text { in temporal } \\
\text { region and } \\
\text { subconical } \\
\text { tubercles in } \\
\text { nuchal region }\end{array}$ & $\begin{array}{l}\text { Flat temporal } \\
\text { scales and low } \\
\text { enlarged } \\
\text { tubercles in } \\
\text { nuchal region }\end{array}$ & $\begin{array}{l}\text { Flat temporal } \\
\text { scales and } \\
\text { low tubercles } \\
\text { surrounded } \\
\text { by granular } \\
\text { scales in } \\
\text { nuchal region }\end{array}$ & $\begin{array}{l}\text { Flat temporal } \\
\text { scales and } \\
\text { enlarged, } \\
\text { slightly keeled } \\
\text { nuchal } \\
\text { tubercles } \\
\text { surrounded by }\end{array}$ & $\begin{array}{l}\text { Flat temporal } \\
\text { scales and } \\
\text { enlarged, } \\
\text { slightly keeled } \\
\text { nuchal } \\
\text { tubercles } \\
\text { surrounded by }\end{array}$ \\
\hline
\end{tabular}




\begin{tabular}{|c|c|c|c|c|c|c|c|c|}
\hline & & & $\begin{array}{l}\text { subconical } \\
\text { tubercles on } \\
\text { each side of } \\
\text { the body }\end{array}$ & & & & granular scales & $\begin{array}{l}\text { small rounded } \\
\text { scales }\end{array}$ \\
\hline $\begin{array}{l}\text { Scales of } \\
\text { dorsum }\end{array}$ & $\begin{array}{l}\text { Vertebral row } \\
\text { of paired, } \\
\text { enlarged, } \\
\text { keeled scales } \\
\text { and two } \\
\text { paravertebral } \\
\text { series of short } \\
\text { oblique rows } \\
\text { of projecting } \\
\text { scales }\end{array}$ & $\begin{array}{l}\text { Two } \\
\text { paravertebral } \\
\text { rows of } \\
\text { tubercles or } \\
\text { spine-like } \\
\text { scales, } \\
\text { separated by } 4- \\
6 \text { small scales }\end{array}$ & $\begin{array}{l}\text { Two } \\
\text { paravertebral } \\
\text { rows of spine- } \\
\text { like scales, } \\
\text { separated by } 5 \\
\text { or mores } \\
\text { irregular scales }\end{array}$ & $\begin{array}{l}\text { Vertebral row } \\
\text { of paired, } \\
\text { enlarged, } \\
\text { smooth scales }\end{array}$ & $\begin{array}{l}\text { Paravertebral } \\
\text { rows formed by } \\
\text { spine-like } \\
\text { scales, } \\
\text { discontinuous } \\
\text { posteriorly }\end{array}$ & $\begin{array}{l}\text { No } \\
\text { continuous } \\
\text { vertebral or } \\
\text { paravertebral } \\
\text { rows of } \\
\text { enlarged } \\
\text { scales: } \\
\text { enlarged } \\
\text { scales } \\
\text { arranged } \\
\text { obliquely in } \\
\text { short series of } \\
3-8 \text { scales } \\
\text { forming } \\
\text { irregular } \\
\text { chevrons on } \\
\text { dorsal field of } \\
\text { body and } \\
\text { broken } \\
\text { undulating } \\
\text { rows of } \\
\text { scales along } \\
\text { dorsolateral } \\
\text { body }\end{array}$ & $\begin{array}{l}\text { Two } \\
\text { paravertebral } \\
\text { rows separated } \\
\text { by } 3-8 \text { small } \\
\text { irregular scales }\end{array}$ & $\begin{array}{l}\text { Two } \\
\text { paravertebral } \\
\text { rows of } \\
\text { tubercular } \\
\text { scales } \\
\text { arranged in } \\
\text { zigzag pattern }\end{array}$ \\
\hline $\begin{array}{l}\text { Scales of } \\
\text { flanks }\end{array}$ & $\begin{array}{l}\text { Enlarged spiny } \\
\text { scales forming } \\
\text { oblique lines }\end{array}$ & $\begin{array}{l}\text { Tubercular } \\
\text { scales forming } \\
\text { oblique lines } \\
\text { on lateral } \\
\text { surface of } \\
\text { body }\end{array}$ & $\begin{array}{l}\text { Series of } \\
\text { spine-like } \\
\text { scales forming } \\
\text { oblique lines } \\
\text { on lateral } \\
\text { surface of } \\
\text { body }\end{array}$ & $\begin{array}{l}\text { Series of } \\
\text { spine-like } \\
\text { scales forming } \\
\text { oblique lines } \\
\text { on lateral } \\
\text { surface of } \\
\text { body }\end{array}$ & $\begin{array}{l}\text { Series of } \\
\text { conical scales } \\
\text { of different } \\
\text { sizes forming } \\
\text { oblique lines on } \\
\text { lateral surface } \\
\text { of body }\end{array}$ & $\begin{array}{l}\text { Alternate } \\
\text { tubercular } \\
\text { scales on } \\
\text { lateral surface } \\
\text { of body }\end{array}$ & $\begin{array}{l}\text { Series of } \\
\text { spine-like } \\
\text { scales forming } \\
\text { oblique lines } \\
\text { on lateral } \\
\text { surface of } \\
\text { body }\end{array}$ & $\begin{array}{l}\text { Series of } \\
\text { tubercular } \\
\text { scales forming } \\
\text { oblique lines } \\
\text { on lateral } \\
\text { surface of } \\
\text { body }\end{array}$ \\
\hline Source & This study & $\begin{array}{l}\text { Köhler et al. } \\
2004\end{array}$ & $\begin{array}{l}\text { Vásquez- } \\
\text { Restrepo et al. } \\
2019\end{array}$ & $\begin{array}{l}\text { Uzzell 1965; } \\
\text { Köhler et al. } \\
\text { 2004; This } \\
\text { study }\end{array}$ & $\begin{array}{l}\text { Köhler et al. } \\
\text { 2004; Vásquez- } \\
\text { Restrepo et al. } \\
\text { 2019; This } \\
\text { study }\end{array}$ & $\begin{array}{l}\text { Fritts et al. } \\
2002\end{array}$ & $\begin{array}{l}\text { Vásquez- } \\
\text { Restrepo et al. } \\
2019\end{array}$ & $\begin{array}{l}\text { Vásquez- } \\
\text { Restrepo et al. } \\
2019\end{array}$ \\
\hline
\end{tabular}




\section{Table 2 (on next page)}

Morphometric data of the type series of Echinosaura fischerorum sp. nov.

Holotype is marked with *. Accompanying the range, the sample size is included in parentheses $(\mathrm{N})$, followed by the mean and standard deviation. All specimens are from the same collection (DHMECN). SVL = snout-vent length; $T R L=$ trunk length; $T A L=$ tail length; $\mathrm{SL}=$ snout length; $\mathrm{HL}=$ head length; $\mathrm{HW}=$ head width; $\mathrm{HUM}=$ humerus length; $\mathrm{FAL}=$ forearm length; $H N D=$ hand length; FEM = femur length; $T I B=$ tibia length; $F T L=$ foot length. 
Table 2. Morphometric data of the type series of Echinosaura fischerorum sp. nov. Holotype is marked with *. Accompanying the range, the sample size is included in parentheses $(\mathrm{N})$, followed by the mean and standard deviation. All specimens are from the same collection (DHMECN). $\mathrm{SVL}=$ snout - vent length; TRL = trunk length; TAL = tail length; $\mathrm{SL}=$ snout length; $\mathrm{HL}=$ head length; HW = head width; HUM = humerus length; FAL = forearm length; HND = hand length; FEM = femur length; TIB = tibia length; FTL = foot length.

\begin{tabular}{|c|c|c|c|c|c|c|c|c|c|c|c|c|c|c|}
\hline \multirow[b]{2}{*}{ Character } & \multicolumn{3}{|c|}{ Males } & \multirow[b]{2}{*}{16110} & \multirow{2}{*}{ Range } & \multicolumn{4}{|c|}{ Females } & \multirow{2}{*}{ Range } & \multicolumn{3}{|c|}{ Juveniles } & \multirow{2}{*}{ Range } \\
\hline & 15208* & 15209 & 15211 & & & 14058 & 14060 & 15210 & 16109 & & 14059 & 14061 & 12767 & \\
\hline SVL & 69 & 62.8 & 54.7 & 63.1 & $\begin{array}{l}69-54.7(4) \\
66.05 \pm 4.17\end{array}$ & 66.8 & 63.8 & 65.2 & 61.4 & $\begin{array}{c}66.8-61.4(4) \\
64.1 \pm 3.81\end{array}$ & 29.6 & 52.7 & 40.5 & $\begin{array}{l}52.7-29.6(3) \\
40.93 \pm 11.56\end{array}$ \\
\hline TRL & 33.6 & 27.2 & 28.2 & 28.1 & $\begin{array}{c}33.6-22.7(4) \\
30.04 \pm 4.52\end{array}$ & 25.5 & 26.1 & 29.5 & 27.6 & $\begin{array}{c}29.5-25.5(4) \\
27.5 \pm 2.82\end{array}$ & 13.1 & 19.6 & 15.9 & $\begin{array}{c}19.6-13.1(3) \\
16.2 \pm 3.26\end{array}$ \\
\hline TAL & 89.5 & 85.2 & 67 & 88.2 & $\begin{array}{c}89.5-67(4) \\
78.25 \pm \\
15.91\end{array}$ & 82.5 & 84 & 88.7 & 91 & $\begin{array}{l}91-82.5(4) \\
86.75 \pm 6.01\end{array}$ & 37.5 & 73.6 & 55.6 & $\begin{array}{l}73.6-37.5(3) \\
55.57 \pm 18.05\end{array}$ \\
\hline SL & 13.7 & 11.8 & 10.8 & 12 & $\begin{array}{c}13.7-10.8(4) \\
12.25 \pm 2.05\end{array}$ & 12.1 & 12.2 & 12.6 & 12 & $\begin{array}{l}12.6-12(4) \\
12.3 \pm 0.42\end{array}$ & 5.7 & 9.4 & 7.3 & $\begin{array}{l}9.4-5.7(3) \\
7.47 \pm 1.86\end{array}$ \\
\hline HL & 20.1 & 17.5 & 17.6 & 18.3 & $\begin{array}{c}20.1-17.5(4) \\
18.8 \pm 1.83\end{array}$ & 18.5 & 17.2 & 17.2 & 16.3 & $\begin{array}{c}18.5-16.3(4) \\
17.4 \pm 1,55\end{array}$ & 8.8 & 15.2 & 11 & $\begin{array}{l}15.2-8.8(3) \\
11.67 \pm 3.25\end{array}$ \\
\hline HW & 13.2 & 12.1 & 10.7 & 11.9 & $\begin{array}{c}13.2-10.7(4) \\
11.95 \pm 1.76\end{array}$ & 11.6 & 10.7 & 10.6 & 11 & $\begin{array}{c}11.6-10.6(4) \\
11.1 \pm 0.70\end{array}$ & 5.2 & 9.5 & 7.1 & $\begin{array}{l}9.5-5.2(3) \\
7.27 \pm 2.15\end{array}$ \\
\hline HUM & 9.7 & 7.9 & 8.4 & 7.9 & $\begin{array}{c}9.7-7.9(4) \\
8.8 \pm 1.27\end{array}$ & 10.9 & 9.3 & 8.4 & 9 & $\begin{array}{l}10.9-8.4(4) \\
9.65 \pm 1.76\end{array}$ & 4.6 & 7.7 & 6.4 & $\begin{array}{l}7.7-4.6(3) \\
6.23 \pm 1.56\end{array}$ \\
\hline FAL & 9.1 & 7.4 & 7.3 & 8.3 & $\begin{array}{c}9.1-7.3(4) \\
8.2 \pm 1.27\end{array}$ & 8 & 7.7 & 7.1 & 8.1 & $\begin{array}{c}8.1-7.1(4) \\
7.6 \pm 0.70\end{array}$ & 3.9 & 6.1 & 4.7 & $\begin{array}{c}6.1-3.9(3) \\
4.9 \pm 1.11\end{array}$ \\
\hline HND & 9.3 & 8.4 & 9 & 8.6 & $\begin{array}{l}9.3-8.4(4) \\
8.85 \pm 0.63\end{array}$ & 9.7 & 14.8 & 8.2 & 9.9 & $\begin{array}{c}14.8-8.2(4) \\
11.5 \pm 4.66\end{array}$ & 4.4 & 8.4 & 5.8 & $\begin{array}{c}8.4-4.4(3) \\
6.2 \pm 2.03\end{array}$ \\
\hline FEM & 12.5 & 11 & 10.7 & 13.1 & $\begin{array}{c}13.1-10.7(4) \\
11.9 \pm 1.69\end{array}$ & 11.6 & 12.1 & 9.6 & 11.2 & $\begin{array}{l}12.1-9.6(4) \\
10.85 \pm 1.76\end{array}$ & 5.5 & 9.6 & 6.3 & $\begin{array}{l}9.6-5.5(3) \\
7.13 \pm 2.17\end{array}$ \\
\hline TIB & 13.7 & 11.4 & 10.9 & 11.3 & $\begin{array}{c}13.7-10.9(4) \\
12.3 \pm 1.98\end{array}$ & 10.7 & 10.6 & 9.9 & 10.8 & $\begin{array}{l}10.8-9-9(4) \\
10.35 \pm 0.63\end{array}$ & 5.3 & 9.8 & 5.8 & $\begin{array}{l}9.8-5.3(3) \\
6.97 \pm 2.47\end{array}$ \\
\hline FTL & 15.7 & 14.7 & 14.9 & 14.2 & $\begin{array}{c}15.7-14.2(4) \\
14.95 \pm 1.06\end{array}$ & 15.2 & 14.9 & 15.5 & 15.4 & $\begin{array}{c}15.5-14.9(4) \\
15.2 \pm 0.42\end{array}$ & 7.3 & 13.8 & 8 & $\begin{array}{c}13.8-7.3(3) \\
9.70 \pm 3.57\end{array}$ \\
\hline
\end{tabular}


Table 3 (on next page)

Lepidotic characters of the type series of Echinosaura fischerorum sp. nov. 
1 Table 3. Lepidotic characters of the type series of Echinosaura fischerorum sp. nov.

2

\begin{tabular}{|c|c|c|c|}
\hline Character & Males & Females & Juveniles \\
\hline Frontal scales & 1 & 1 & 1 \\
\hline Large chin shields & 2 & 2 & 2 \\
\hline Gulars in transverse row & $19-20$ & $17-21$ & $18-19$ \\
\hline Internasal scales & 1 & 1 & 1 \\
\hline Frontonasal scales & 2 & 2 & 2 \\
\hline Frontoparietal scales & 2 & 2 & 2 \\
\hline Supraoculars & 3 & 3 & 3 \\
\hline Presupraoculars & 1 & 1 & 1 \\
\hline Postmentals & 1 & 1 & 1 \\
\hline Mentals & 1 & 1 & 1 \\
\hline Scales between paravertebral edges & $10-11$ & $10-11$ & $9-10$ \\
\hline Supralabial scales & $5-5$ & $5-5$ & $5-5$ \\
\hline Infralabial scales & $4-4$ & $4-4$ & $4-4$ \\
\hline Femoral pores & $8-9$ & 0 & $7-8$ \\
\hline Lamellae under the fourth finger: left, right & $16-18 / 14-18$ & $16-18 / 15-17$ & $15-18 / 14-17$ \\
\hline Lamellae under the fourth toe: left, right & $24-26$ & $24-27 / 24-26$ & $24-25 / 23-26$ \\
\hline Subcaudal scales per autotomic segment & 3 & 3 & 3 \\
\hline
\end{tabular}

3 
Figure 1

Phylogeny of Cercosaurinae, with a close-up of Echinosaura.

Maximum clade credibility tree obtained from a Bayesian analysis of 148 taxa and 1,935 characters. Numbers above branches are Bayesian posterior probability (PP) values and those below branches are ML bootstrap support (BS) values. 

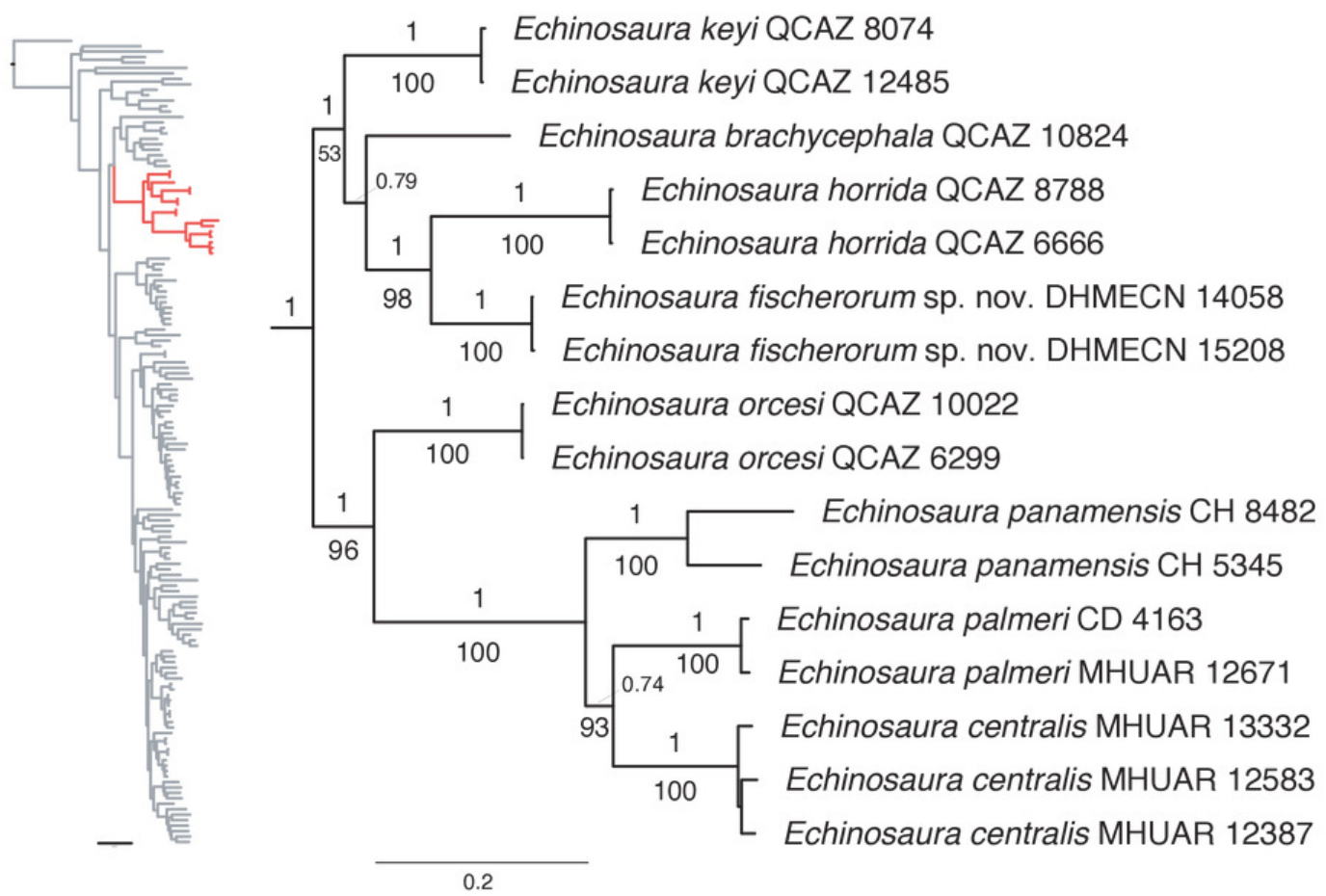
Figure 2

Holotype of Echinosaura fischerorum sp. nov. (male, DHMECN 15208) in dorsal (upper left), ventral (upper right), and lateral (bottom) views.

Scale bars $=10 \mathrm{~mm}$. Photographs by MYM. 

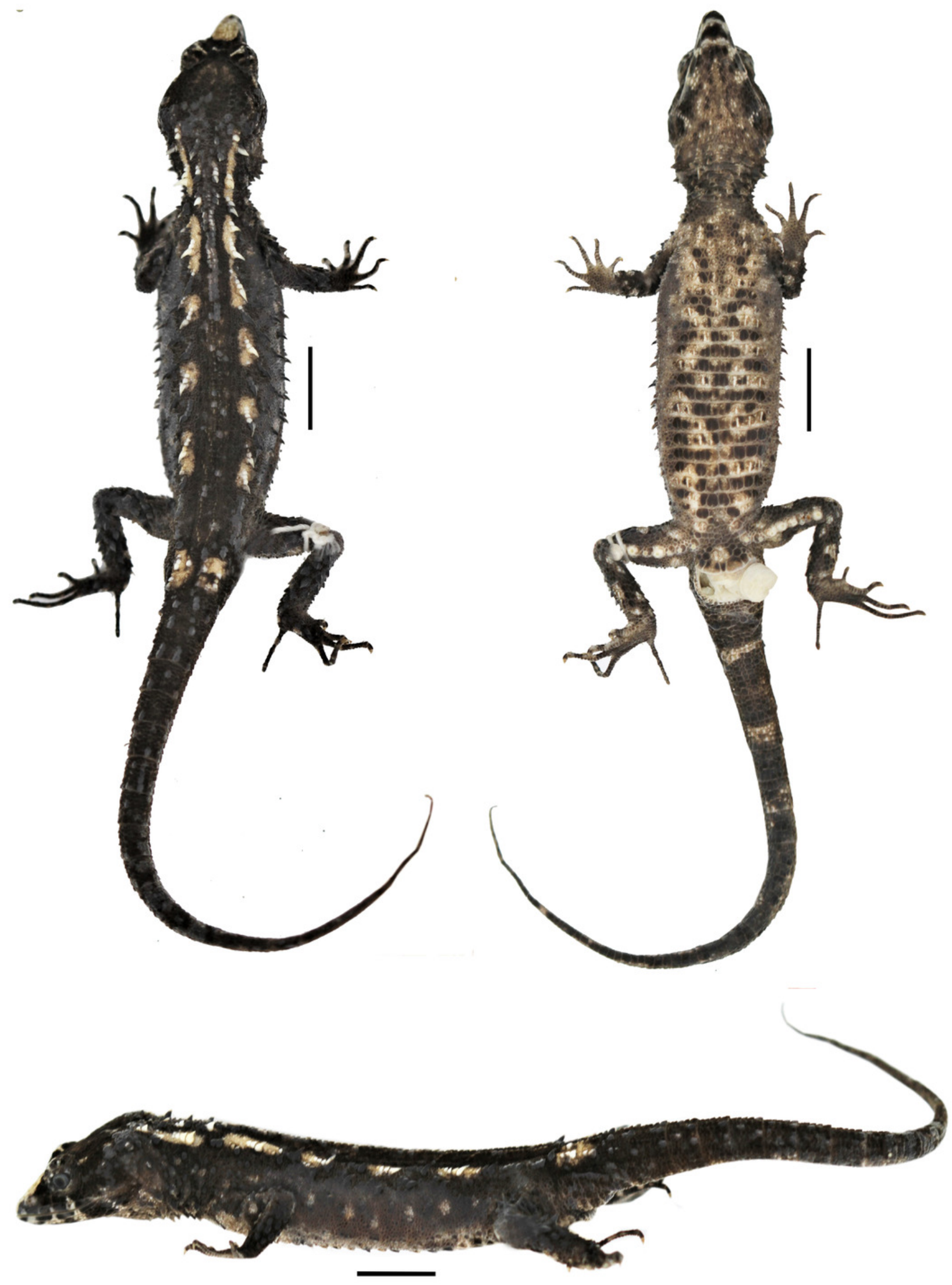
Figure 3

Head of the holotype of Echinosaura fischerorum sp. nov. (male, DHMECN 15208).

(A) dorsal view, (B) lateral view and (C) ventral view. Scale bar $=10 \mathrm{~mm}$. Infralabial and mental scales are shown in gray in ventral view. Illustrations by MYM.
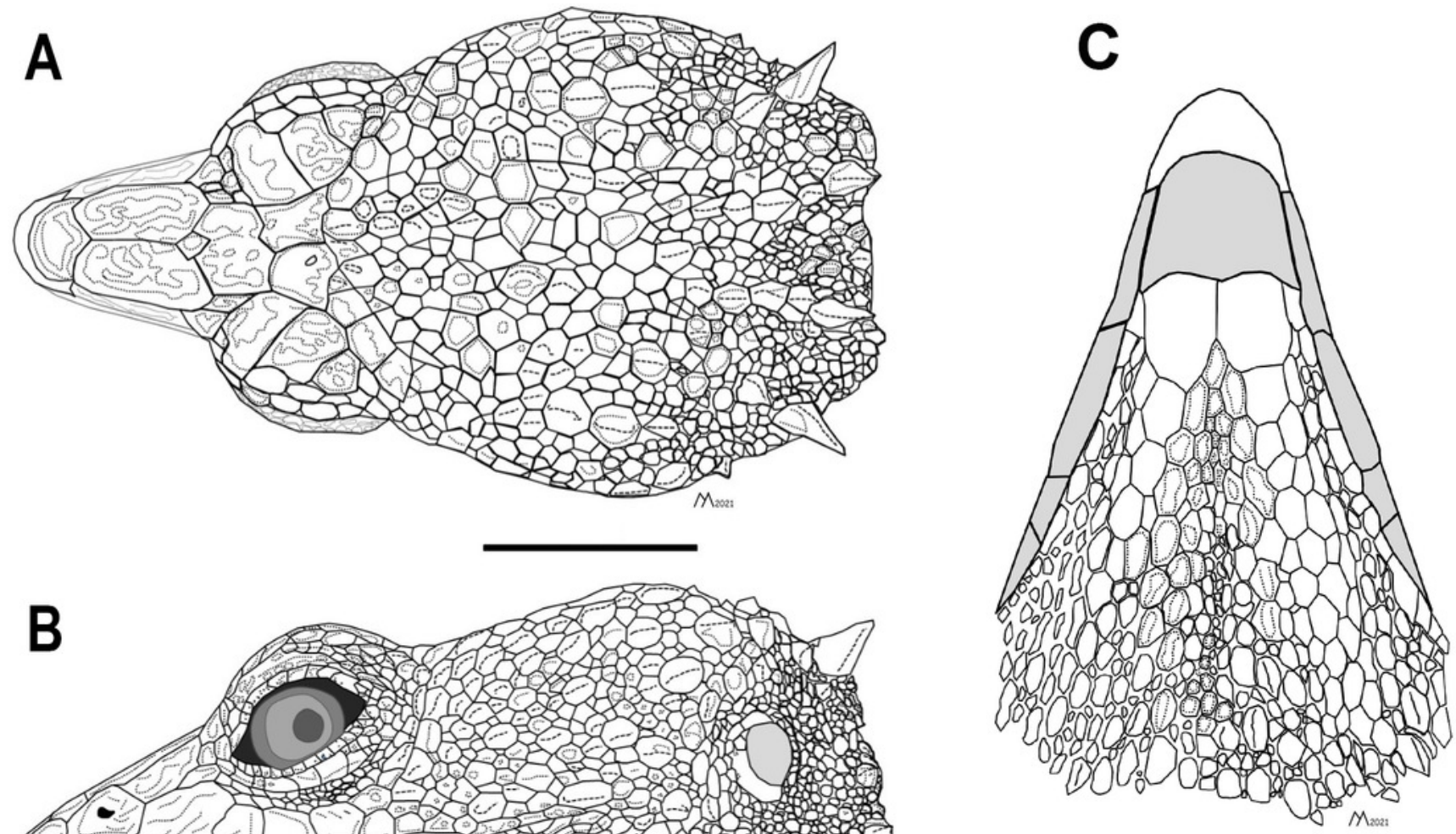
Figure 4

Preserved type specimens of Echinosaura fischerorum sp. nov. showing color variation in dorsal view.

Top (males): DHMECN 15208 (Holotype), DHMECN 15209 (Paratype), DHMECN 15211 (Paratype); middle (females): DHMECN 15210 (Paratype), DHMECN 14058 (Paratype), DHMECN 14060 (Paratype); bottom (juveniles): DHMECN 14061 (Paratype), DHMECN 12767 (Paratype), DHMECN 14059 (Paratype). Scale bars $=10 \mathrm{~mm}$. Photographs by MYM. 

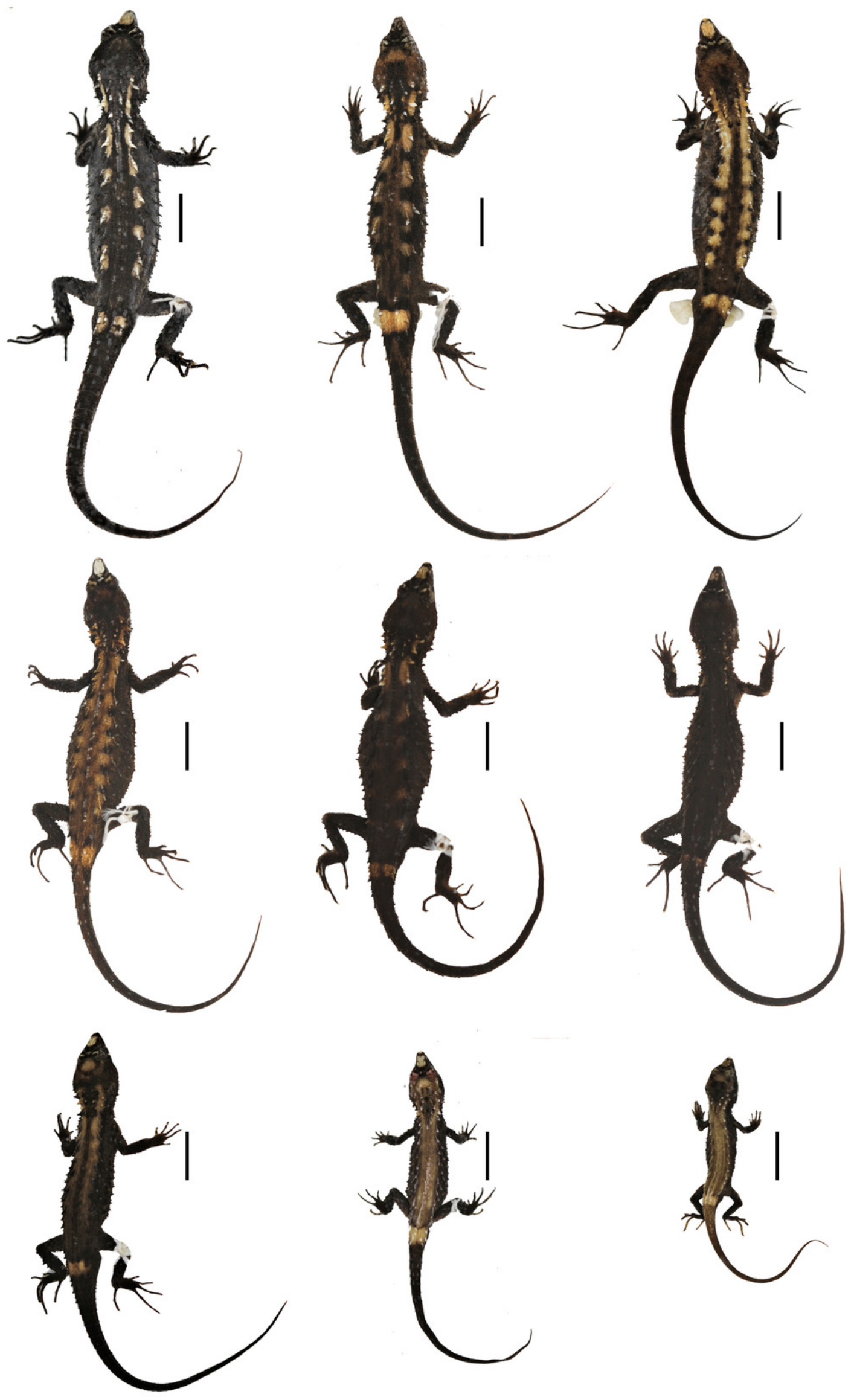

Peer) reviewing PDF | (2021:08:65159:1:1:NEW 18 Oct 2021) 
Figure 5

Preserved type specimens of Echinosaura fischerorum sp. nov. showing color variation in ventral view.

Top (males): DHMECN 15208 (Holotype), DHMECN 15209 (Paratype), DHMECN 15211 (Paratype); middle (females): DHMECN 15210 (Paratype), DHMECN 14058 (Paratype), DHMECN 14060 (Paratype); bottom (juveniles): DHMECN 14061 (Paratype), DHMECN 12767 (Paratype), DHMECN 14059 (Paratype). Photographs by MYM. 

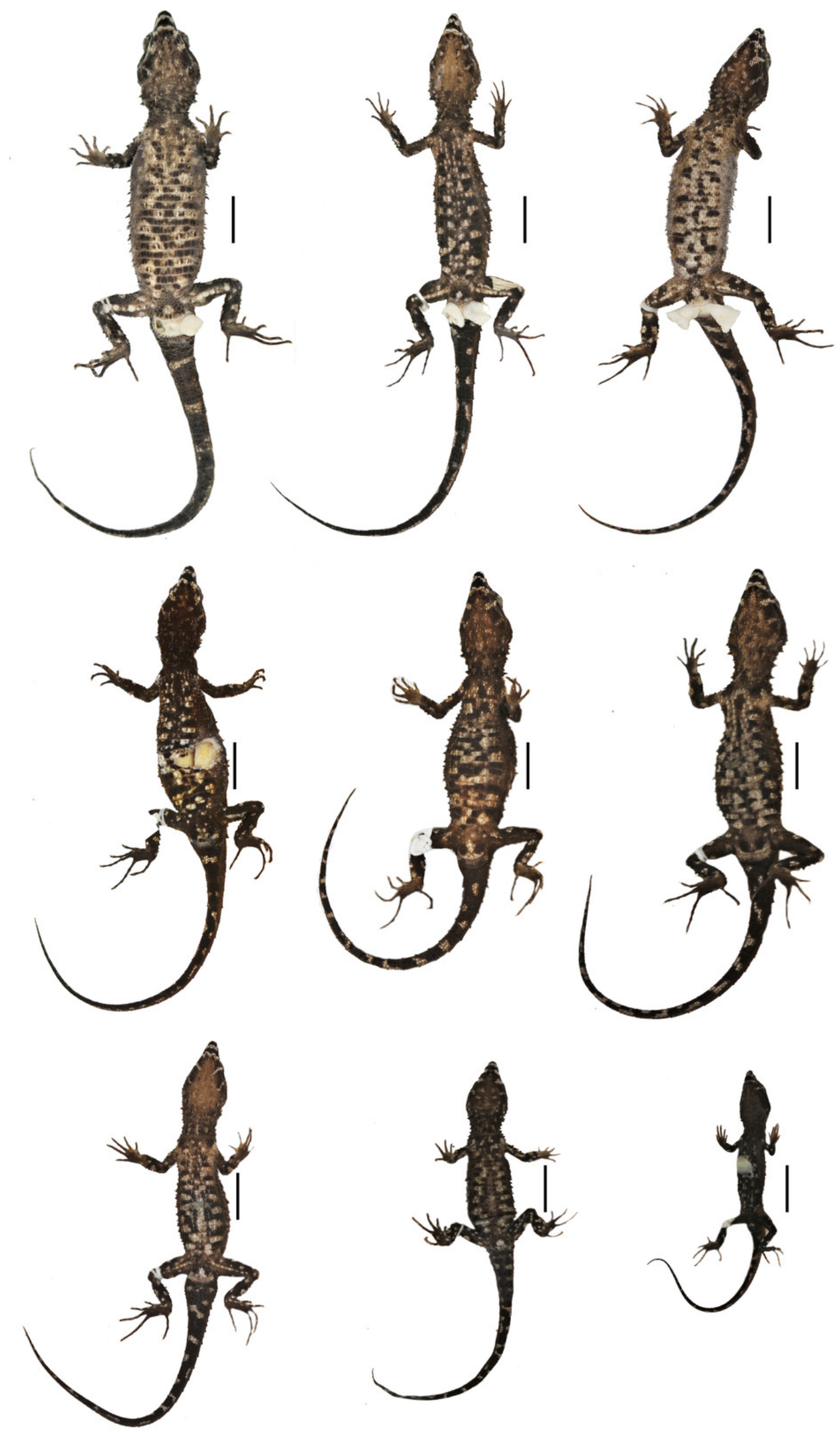


\section{Figure 6}

Live type specimens of Echinosaura fischerorum sp. nov. showing color variation in dorsal view.

(A) DHMECN 15208, male (Holotype); (B) DHMECN 15209, male; (C) DHMECN 15211, male;

(D) DHMECN 16109, female; (E) DHMECN 16110, male. Scale bars $=10 \mathrm{~mm}$. Photographs by $\operatorname{JPRP}(A, B, C) ; \operatorname{MAUM}(D) ;$ Andrew Better (E).
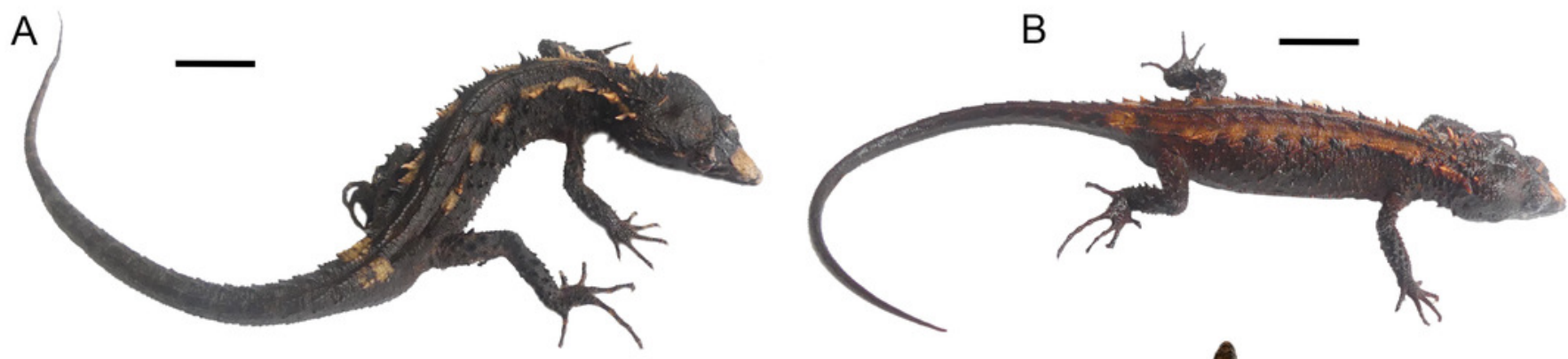

C

D
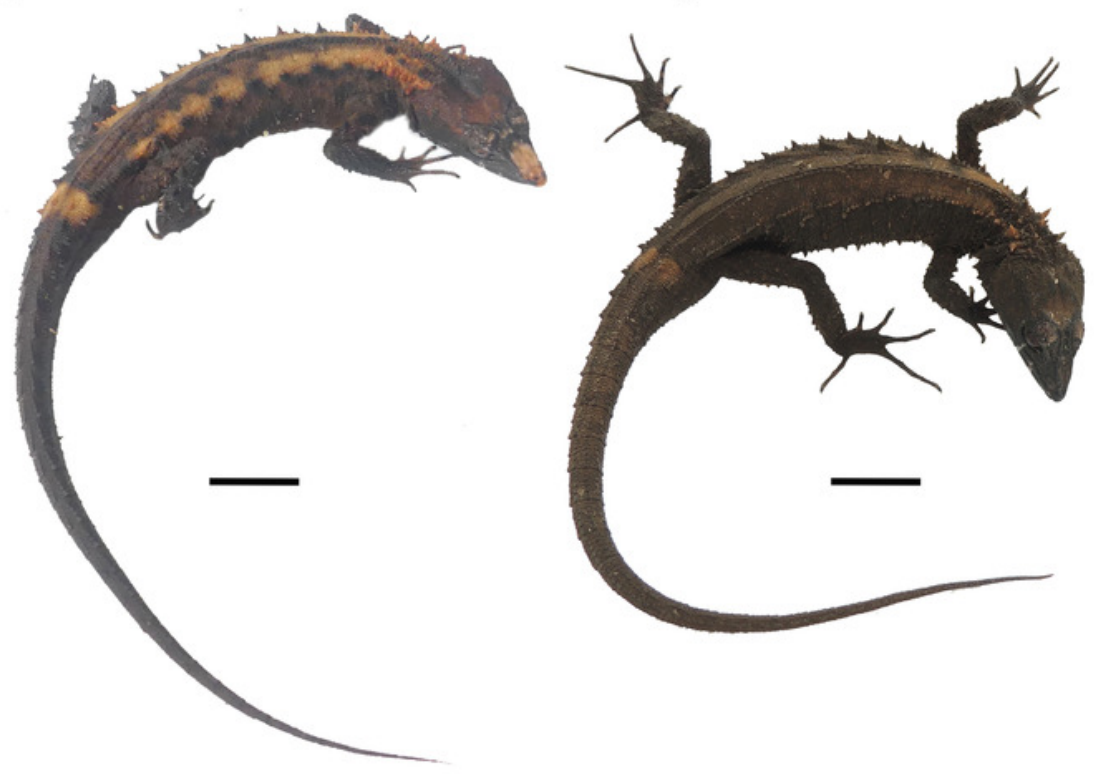

$\mathrm{E}$

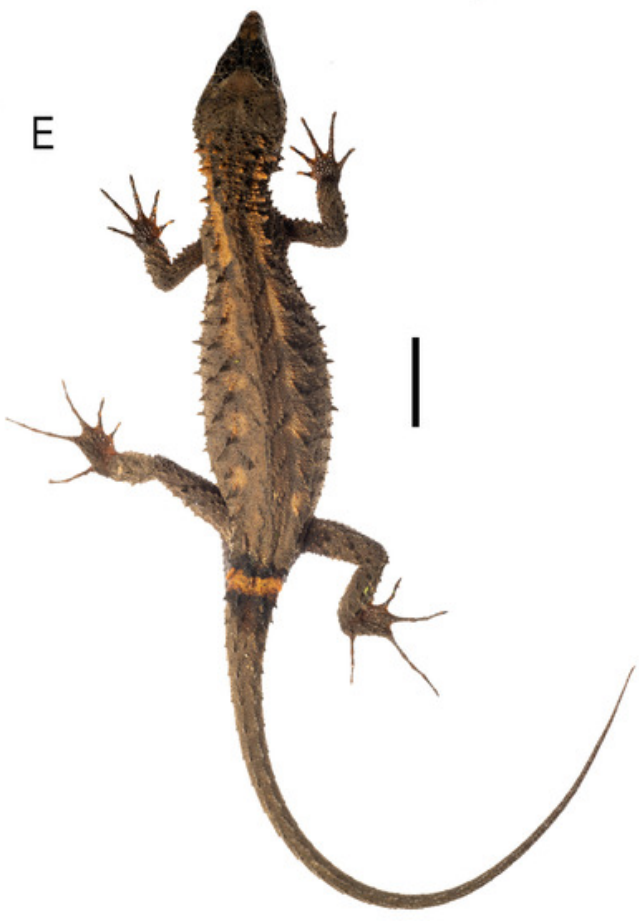




\section{Figure 7}

Right hemipenis of male holotype of Echinosaura fischerorum sp. nov. (DHMECN 15208, Holotype) in (A) asulcate, (B) lateral, (C) sulcate, and (D) apical views.

Scale bar $=10 \mathrm{~mm}$. Photographs by Morris Flecks.

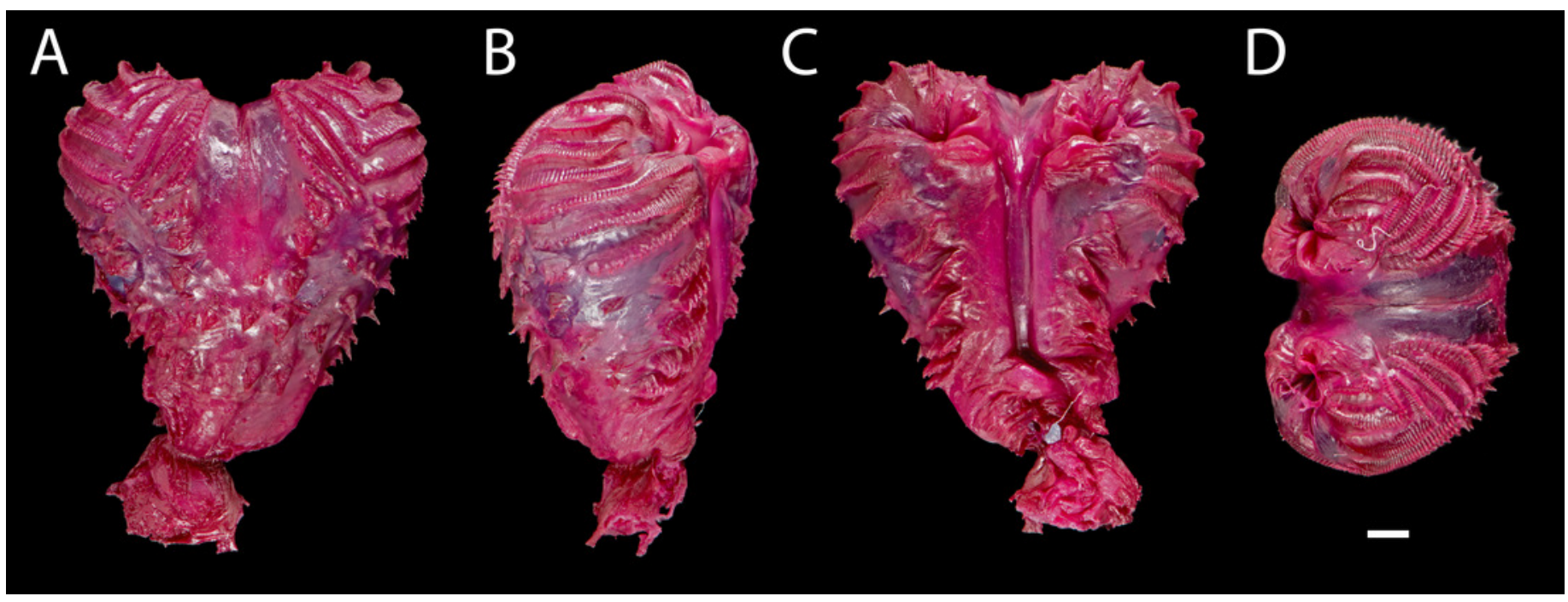




\section{Figure 8}

Cranial skeleton of female paratype (DHMECN 15210) of Echinosaura fischerorum sp. nov.

The skull is shown without mandible in (A) dorsal, (B) ventral, (C) lateral views. Bo $=$ basioccipital; $\mathrm{Ec}=$ ectopterygoid; $\mathrm{Ep}=$ epipterygoid; $\mathrm{F}=$ frontal; $\mathrm{J}=$ jugal; $\mathrm{Mx}=$ maxilla; $\mathrm{N}=$ nasal; Os = orbitosphenoid; Ot = otoccipital; $\mathrm{P}=$ parietal; $\mathrm{Pa}=$ palatine; $\mathrm{Pfr}=$ postfrontal; $\mathrm{Po}$ $=$ postorbital; $\mathrm{Pr}=$ prootic; $\mathrm{Prf}=$ prefrontal; $\mathrm{Ps}=$ parabasisphenoid; $\mathrm{Pt}=$ pterygoid; $\mathrm{Px}=$ premaxilla; $\mathrm{Q}=$ quadrate; $\mathrm{Sc}=$ scleral ossicles; $\mathrm{Sm}=$ septomaxilla; $\mathrm{So}=$ supraoccipital; $\mathrm{Sq}=$ squamosal; St $=$ supratemporal; Stp $=$ stapes; Vo $=$ vomers. Scale bars $=1 \mathrm{~mm}$. 


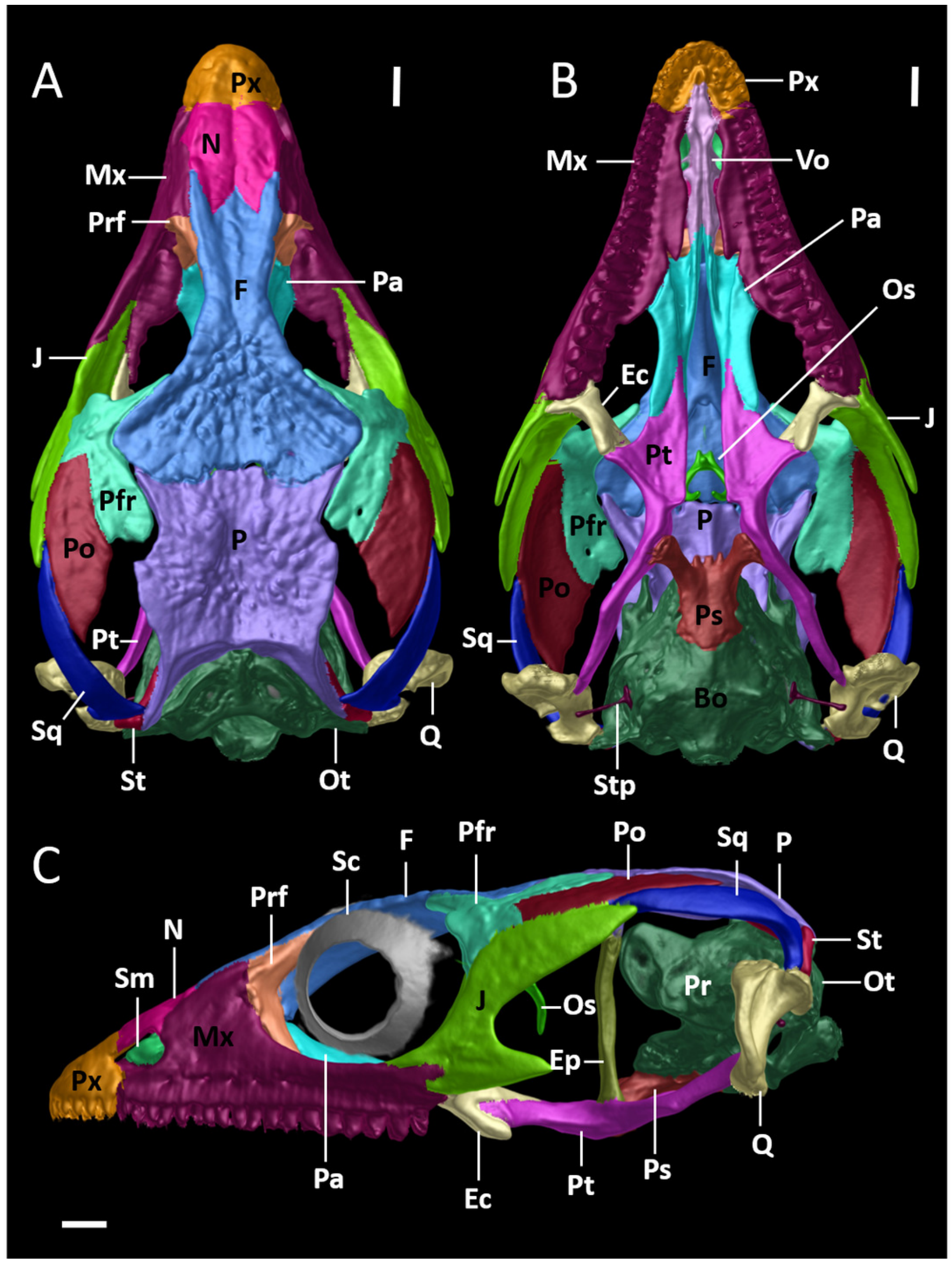




\section{Figure 9}

Cranial skeleton of female paratype (DHMECN 15210) of Echinosaura fischerorum sp. nov.

The skull is shown in (A) anterior and (B) posterior views. $A n=$ angular; $B o=$ basioccipital; $\mathrm{Co}=$ coronoid; $\mathrm{D}=$ dentary; $\mathrm{Ep}=$ epipterygoid; $\mathrm{F}=$ frontal; $\mathrm{J}=$ jugal; $\mathrm{Mx}=$ maxilla; $\mathrm{N}=$ nasal; Ot = otoccipital; $\mathrm{P}=$ parietal; $\mathrm{Pfr}=$ postfrontal; $\mathrm{Po}=$ postorbital; $\mathrm{Pr}=$ prootic; $\mathrm{Ps}=$ parabasisphenoid; $\mathrm{Pt}=$ pterygoid; $\mathrm{Px}=$ premaxilla; $\mathrm{Rp}=$ retroarticular process; $\mathrm{Q}=$ quadrate; $\mathrm{San}=$ surangular; $\mathrm{Sp}=$ splenial; $\mathrm{Sq}=$ squamosal; $\mathrm{St}=$ supratemporal; $\mathrm{Stp}=$ stapes. Scale bar $=1 \mathrm{~mm}$. 
A

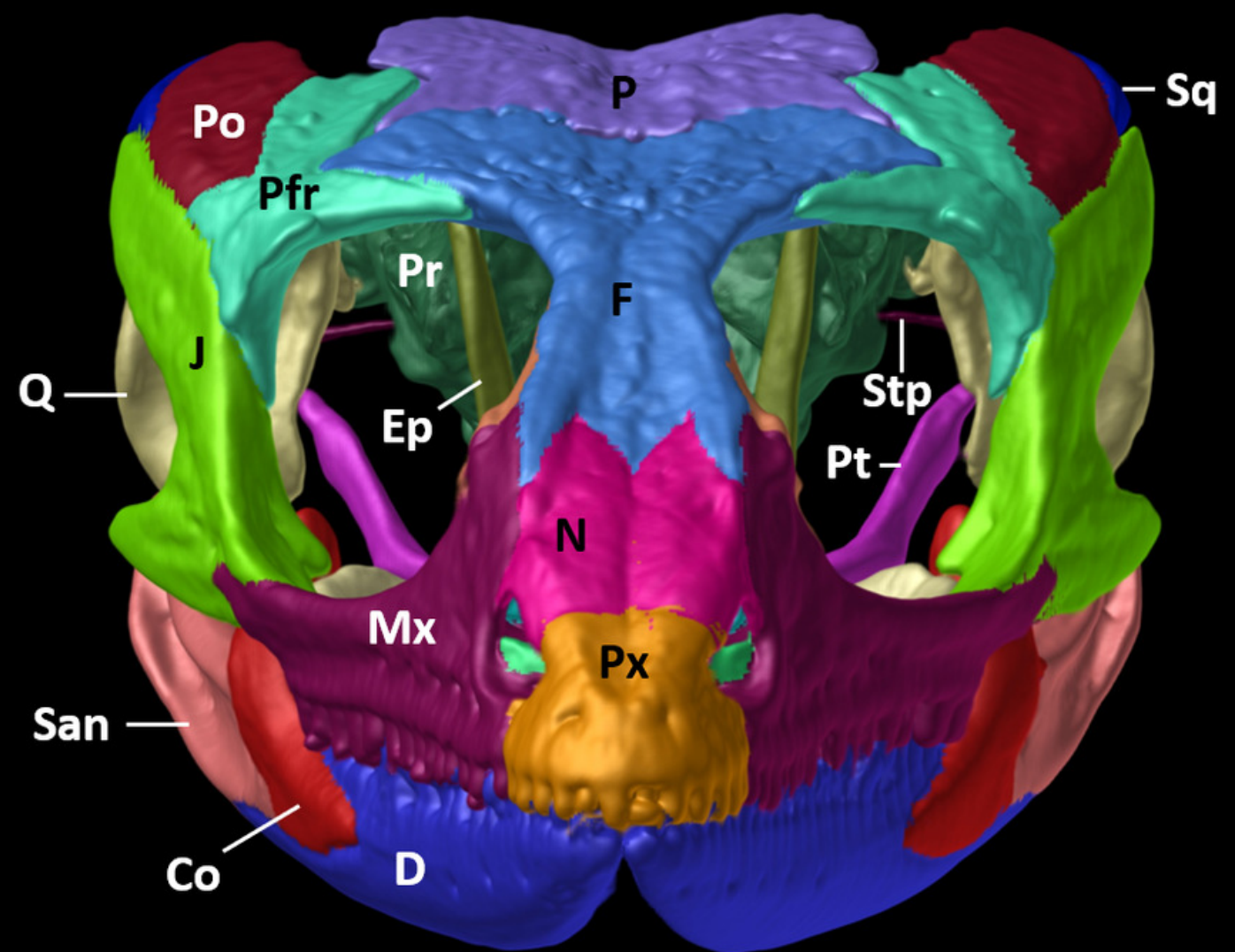

B

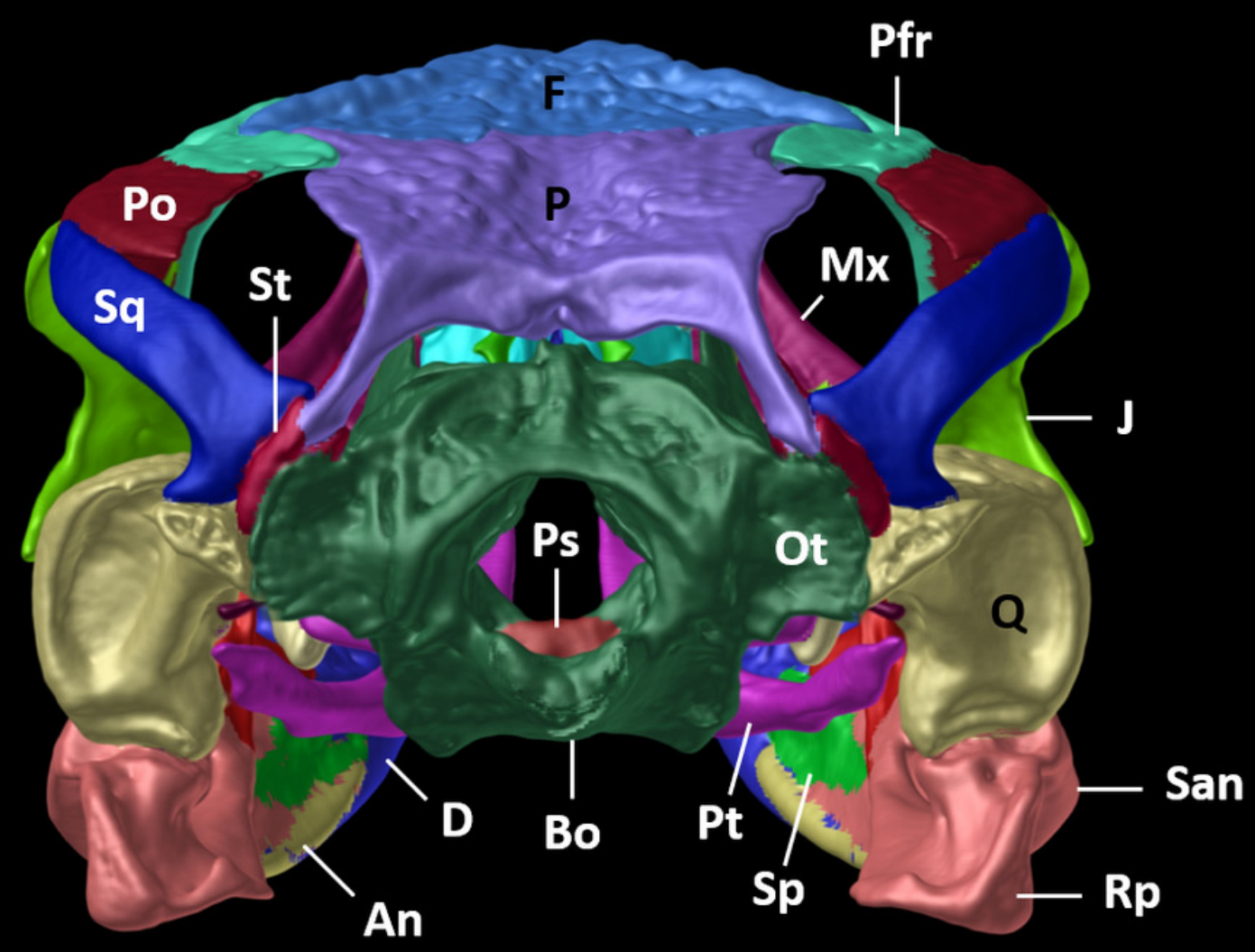




\section{Figure 10}

Mandible of female paratype (DHMECN 15210) of Echinosaura fischerorum sp. nov. in (A) dorsal, (B) ventral, (C) lateral, and (D) medial views.

$\mathrm{An}=$ angular; $\mathrm{Co}=$ coronoid; $\mathrm{D}=$ dentary; $\mathrm{Rp}=$ retroarticular process; San = surangular; $\mathrm{Sp}$ = splenial. Scale bar $=1 \mathrm{~mm}$. 
A

B

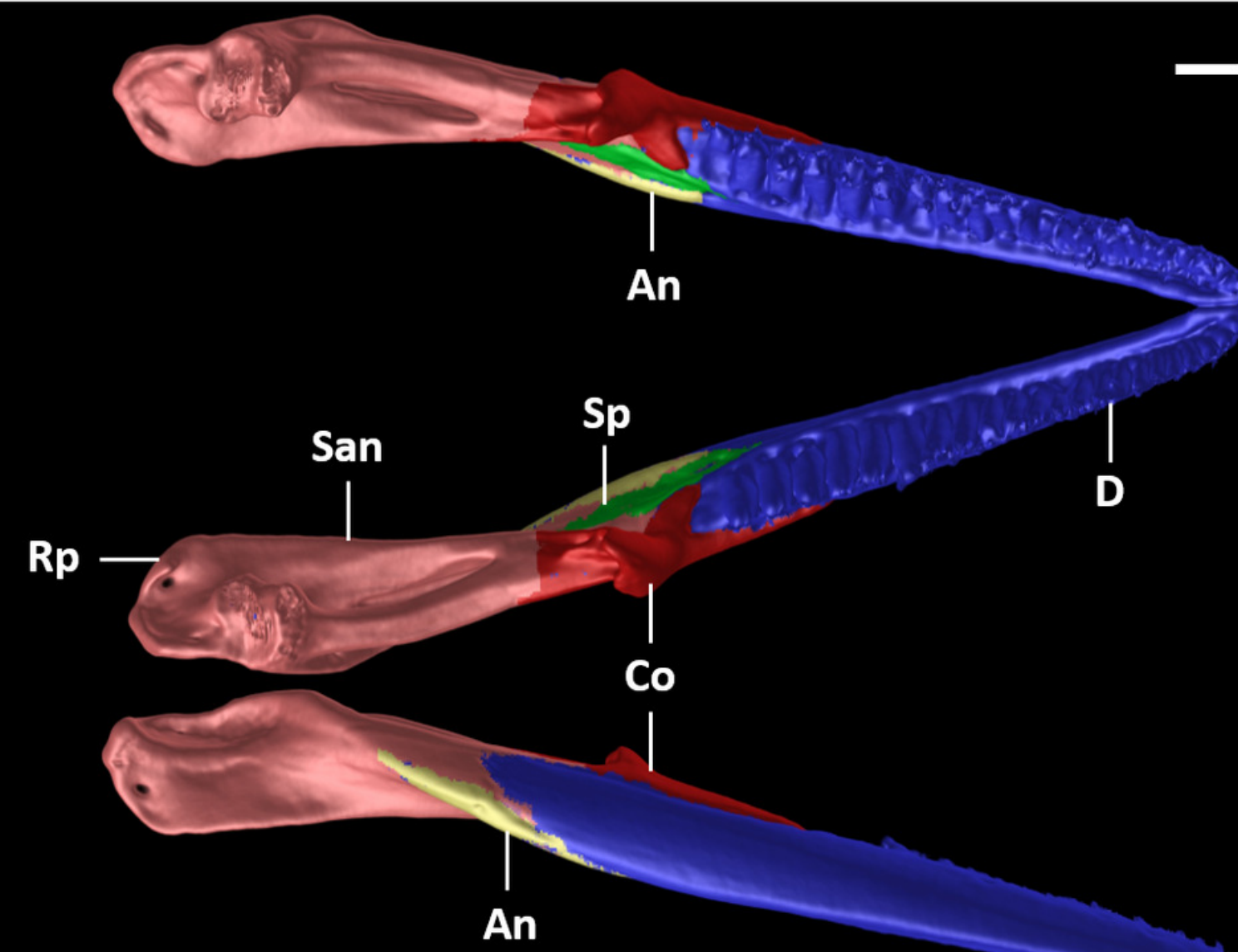

C

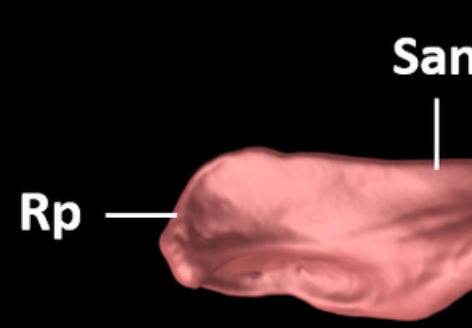

D

D
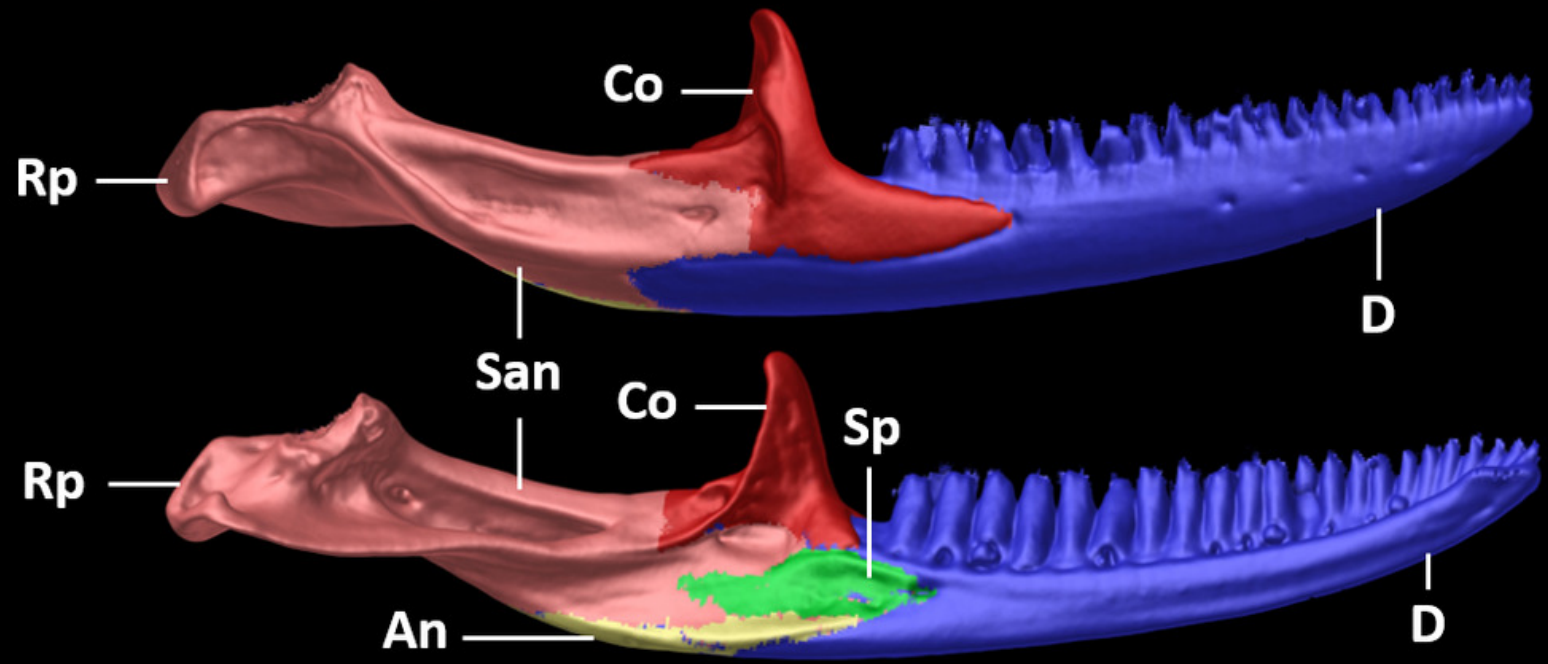


\section{Figure 11}

Heads of seven species of Echinosaura in dorsal (left) and lateral (right) views.

(A) Echinosaura fischerorum sp. nov. (DHMECN 15208, Holotype), (B) E. horrida (ZFMK 43763), (C) E. brachycephala (ZFMK 46370, Paratype), (D) E. keyi (UIMNH 80451, Holotype), (E) E. palmeri (BMNH 1923.10.12.14), (F) E. panamensis (ZFMK 52200), (G) E. orcesi (NMW 32000:1, Paratype). Scale bar $=5 \mathrm{~mm}$. Photographs by MYM (A); Morris Flecks (B, C, E-G); Chris Phillips (D). 


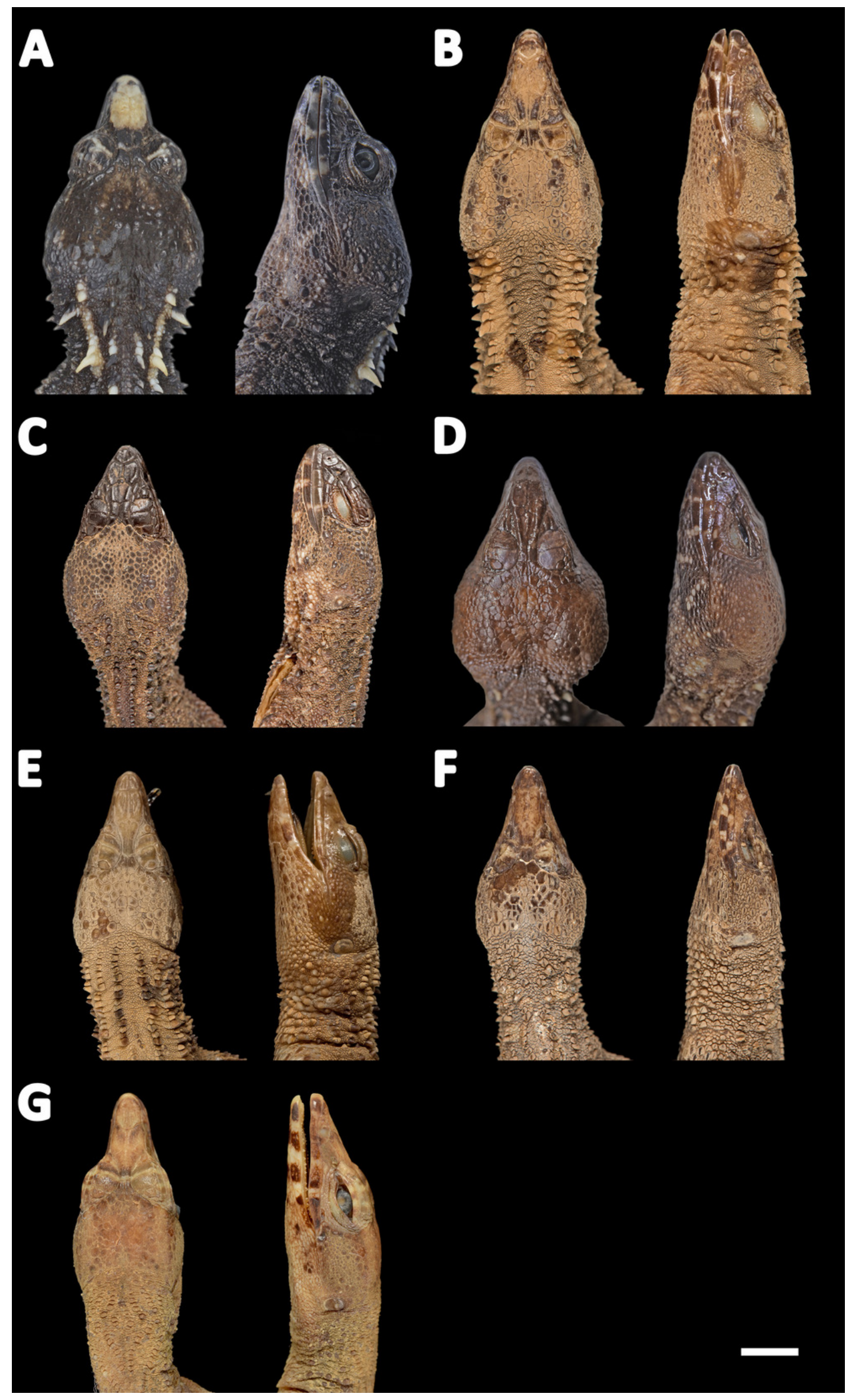

Peer] reviewing PDF | (2021:08:65159:1:1:NEW 18 Oct 2021) 


\section{Figure 12}

Midbody of seven species of Echinosaura in dorsal view.

(A) Echinosaura fischerorum sp. nov. (DHMECN 15209, Paratype), (B) E. horrida (ZFMK 43763), (C) E. brachycephala (ZFMK 46370, Paratype), (D) E. keyi (UIMNH 80451, Holotype), (E) E. palmeri (BMNH 1923.10.12.14), (F) E. panamensis (ZFMK 52200), (G) E. orcesi (NMW 32000:2, Paratype). Scale bar $=5 \mathrm{~mm}$. Photographs by MYM (A); Morris Flecks (B, C, E-G); Chris Phillips (D).

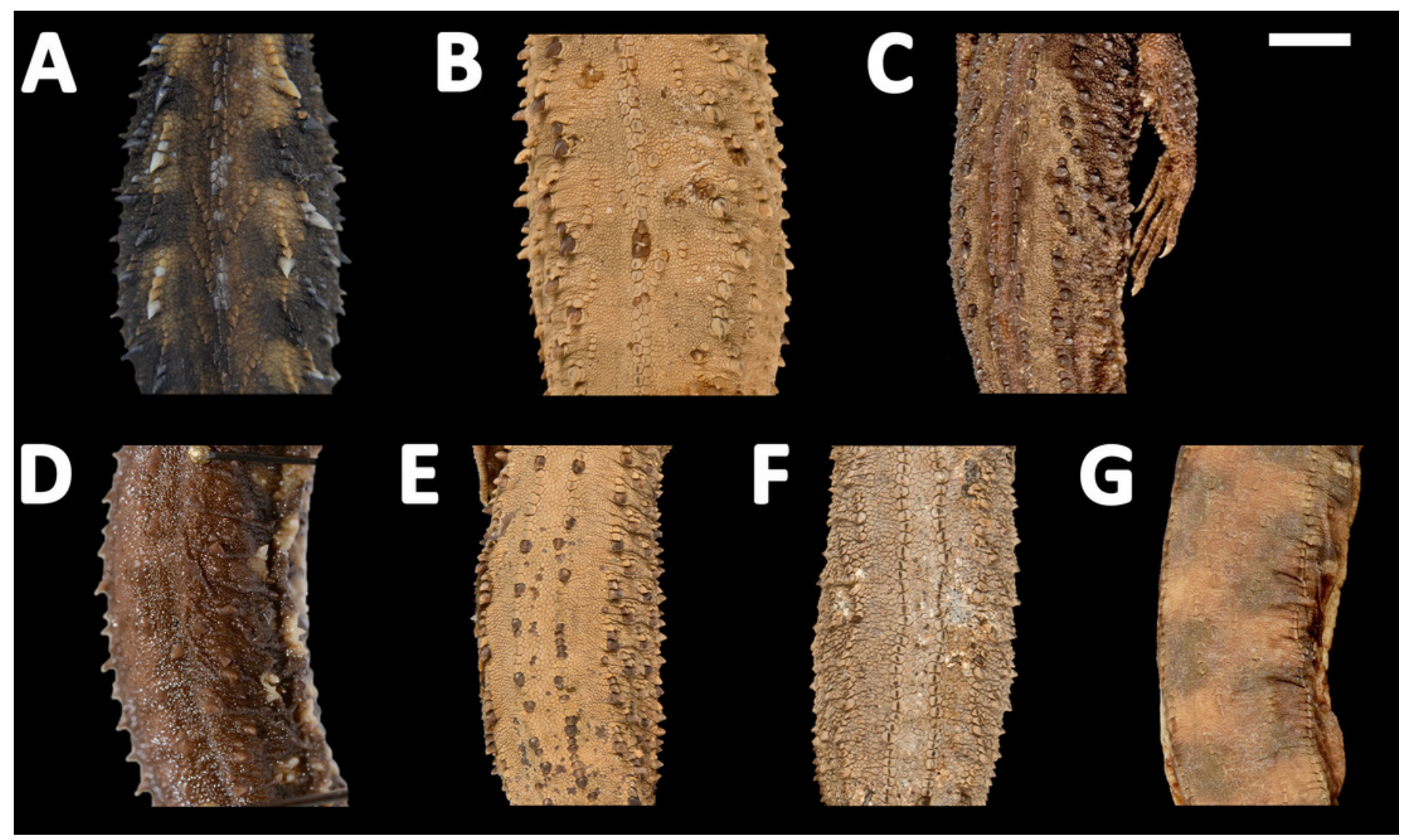




\section{Figure 13}

Tails of seven species of Echinosaura in dorsal (left) and ventral (right) views.

(A) Echinosaura fischerorum sp. nov. (DHMECN 15208, Holotype), (B) E. horrida (ZFMK 43763), (C) E. brachycephala (ZFMK 46370, Paratype), (D) E. keyi (UIMNH 80451, Holotype), (E) E. palmeri (BMNH 1923.10.12.14), (F) E. panamensis (ZFMK 52200), (G) E. orcesi (NMW 32000:2, Paratype). Scale bar $=5 \mathrm{~mm}$. Photographs by MYM (A); Morris Flecks (B, C, E-G); Chris Phillips (D). 


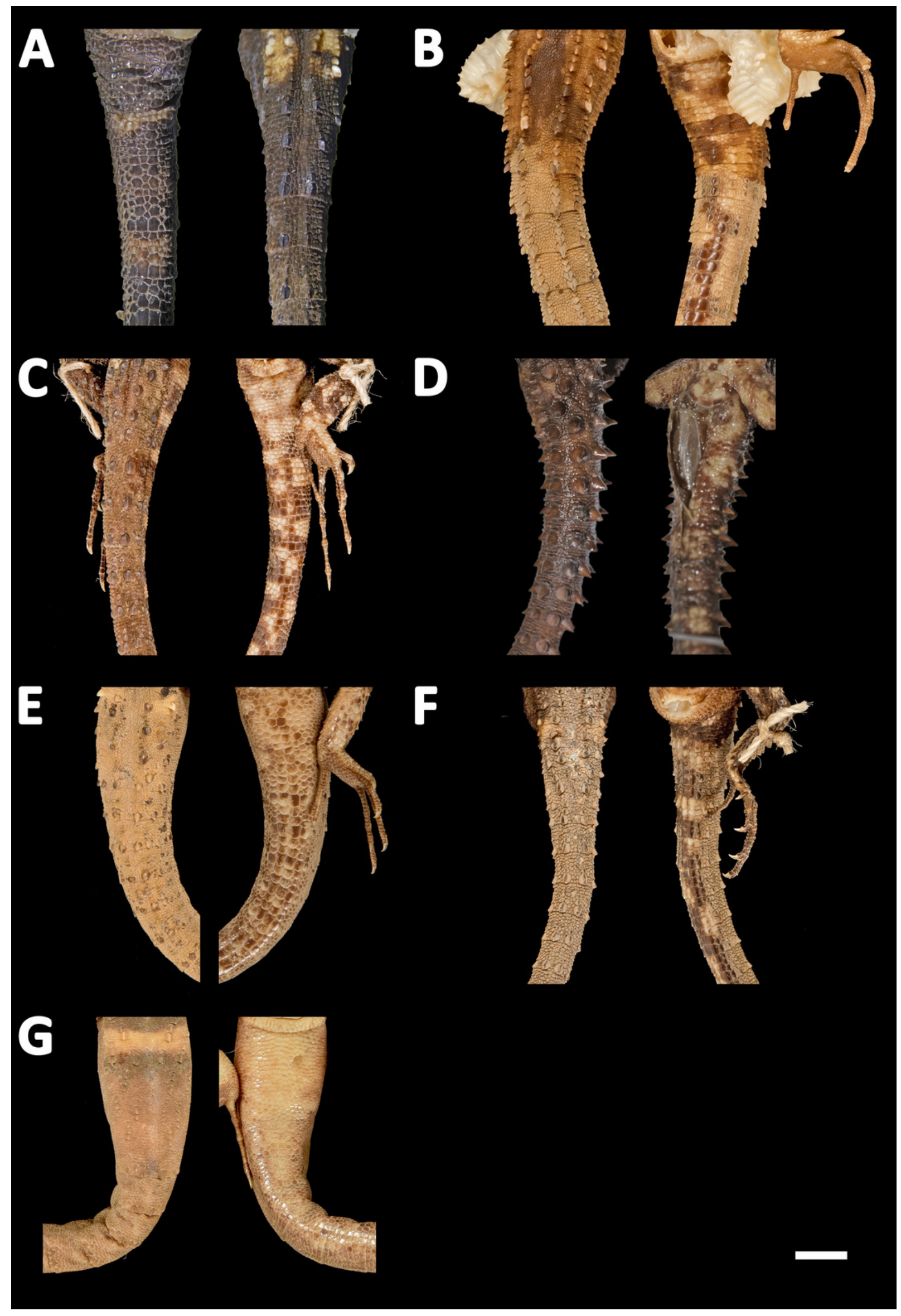

PeerJ reviewing PDF | (2021:08:65159:1:1:NEW 18 Oct 2021) 


\section{Figure 14}

Live specimens of six species of Echinosaura.

(A) E. fischerorum sp. nov., male (no voucher), Reserva Manduriacu, Pichincha, Ecuador; (B) E. horrida, male (DHMECN 13913), Cerro Zapallo, Esmeraldas, Ecuador; (C) E. palmeri, male (no voucher), Timbiqui, Colombia; (D) E. brachycephala, male (QCAZ 11911), Reserva Ecológica Bosque Nublado Santa Lucía, Pichincha, Ecuador; (E) E. keyi, male (QCAZ 8074), Reserva Otokiki, Esmeraldas, Ecuador; (F) E. orcesi, male (QCAZ 15026), Reserva Tesoro Escondido, Esmeraldas, Ecuador. Photographs by MYM (B); Jaime Culebras (A, C); Diego Quirola (D, E); Santiago R. Ron (F). 


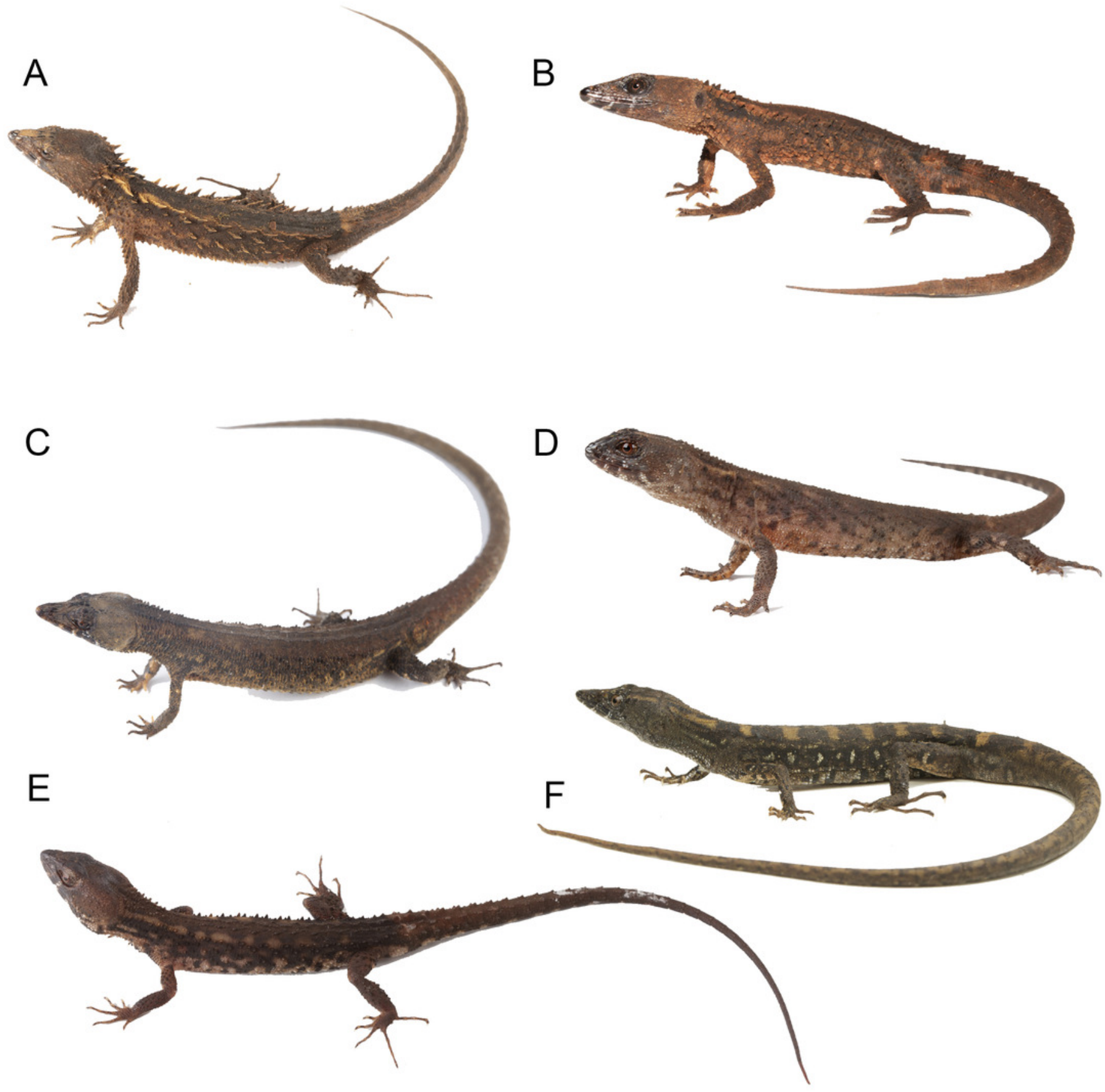




\section{Figure 15}

Pectoral girdles of female paratype DHMECN 15210 (A, B) and male holotype DHMECN 15208 (C, D) of Echinosaura fischerorum sp. nov. in ventral (left) and dorsal (right) views.

Acf = anterior coracoid fenestra; $\mathrm{Cf}$ = coracoid fenestra; $\mathrm{Cl}$ = clavicle; $\mathrm{Ep}=$ epicoracoid; $\mathrm{Gf}=$ glenoid fossa; In = interclavicle; Pcf = posterior coracoid fenestra; R = ribs; Sc = scapulocoracoid; $\mathrm{Scf}=$ scapula-coracoid fenestra; $\mathrm{Sf}$ = sternal fenestra; $\mathrm{Sp}=$ suprascapula; St $=$ Sternum; Xs $=$ xiphisternum. Scale bars $=5 \mathrm{~mm}$. 


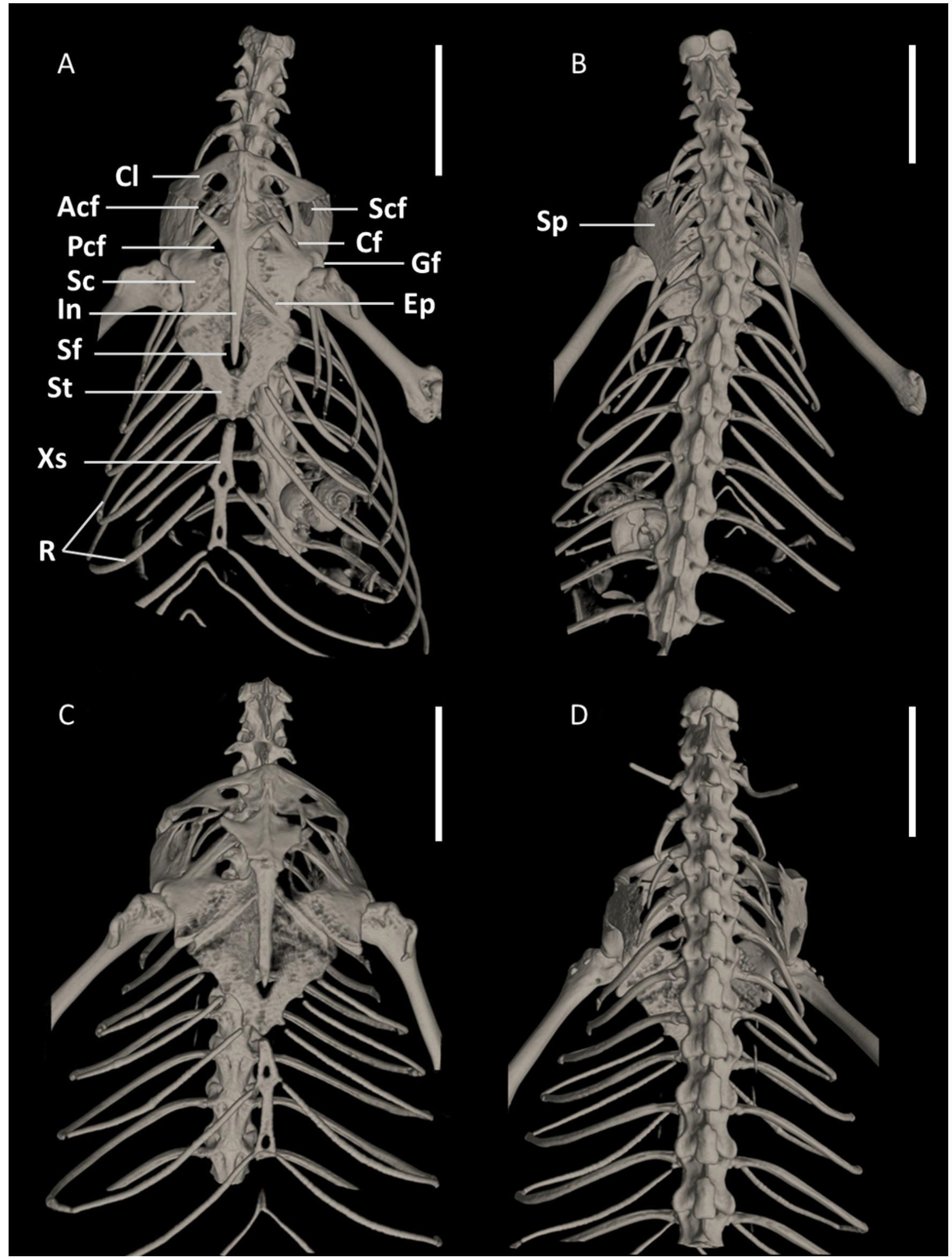




\section{Figure 16}

X-ray images of Echinosaura fischerorum sp. nov. (A) Male holotype (DHMECN 15208); (B) female paratype (DHMECN 15210).

Red arrows show snail shells in the stomach; green arrows show eggs.
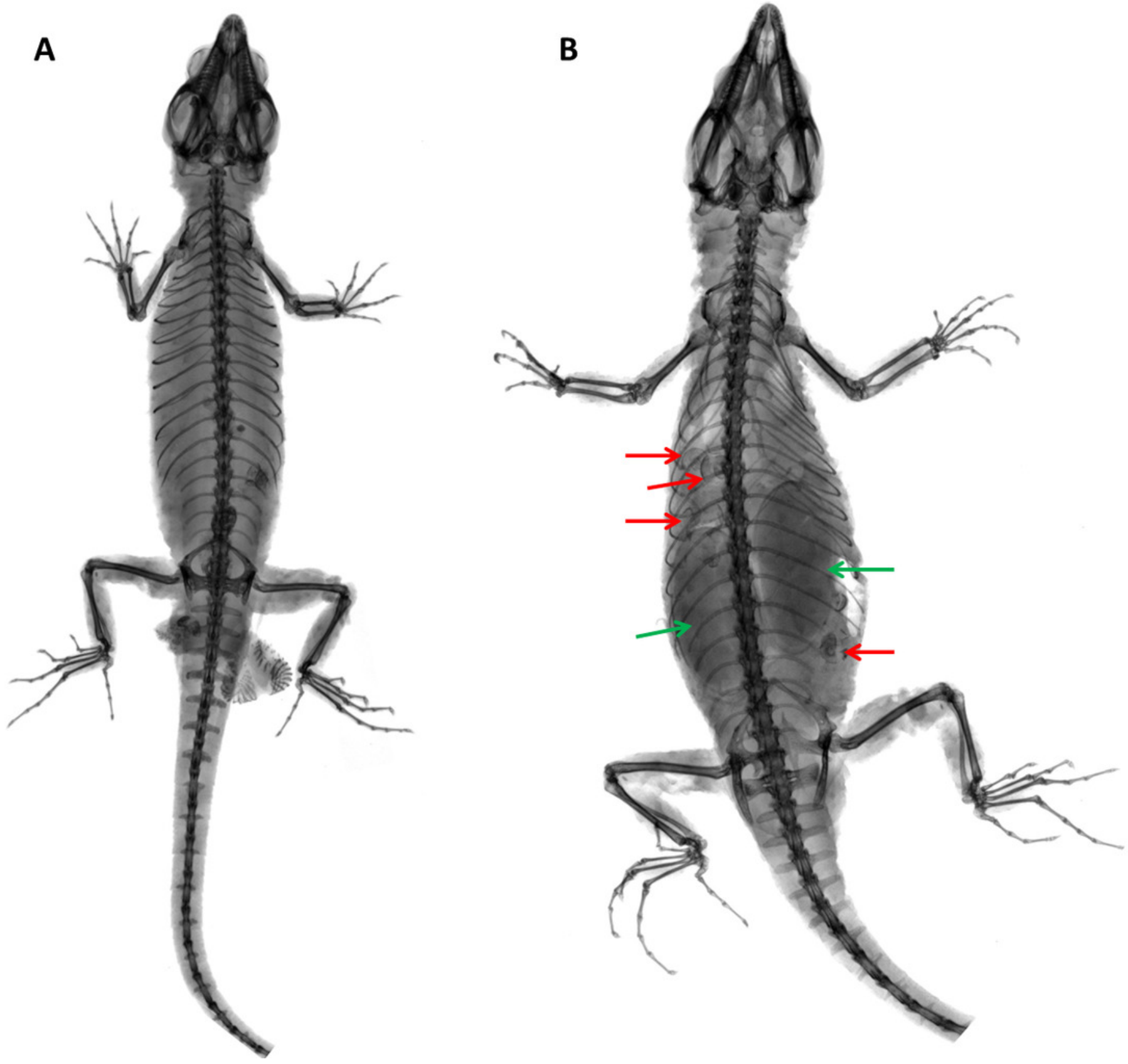
Figure 17

Map of distribution of species of Echinosaura in Ecuador. 


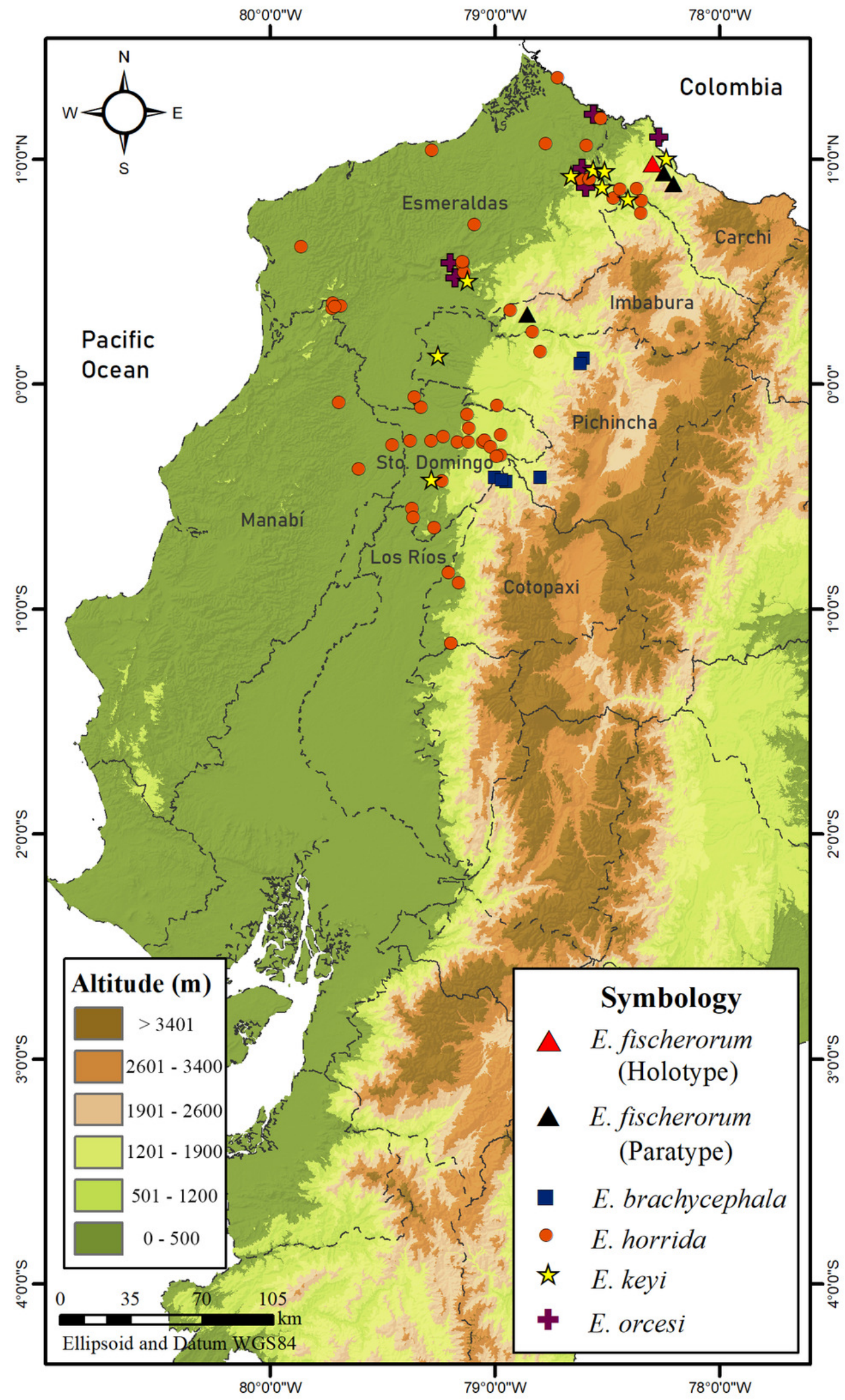

Peer) reviewing PDF | (2021:08:65159:1:1:NEW 18 Oct 2021) 